\title{
Potential Climatic Impact of Organic Haze on Early Earth
}

\author{
Christa A. Hasenkopf,, ${ }^{1,2}$ Miriam A. Freedman, ${ }^{2, *}$ Melinda R. Beaver, ${ }^{3}$ \\ Owen B. Toon, ${ }^{1,4}$ and Margaret A. Tolbert ${ }^{2,5}$
}

\begin{abstract}
We have explored the direct and indirect radiative effects on climate of organic particles likely to have been present on early Earth by measuring their hygroscopicity and cloud nucleating ability. The early Earth analog aerosol particles were generated via ultraviolet photolysis of an early Earth analog gas mixture, which was designed to mimic possible atmospheric conditions before the rise of oxygen. An analog aerosol for the presentday atmosphere of Saturn's moon Titan was tested for comparison. We exposed the early Earth aerosol to a range of relative humidities (RHs). Water uptake onto the aerosol was observed to occur over the entire $\mathrm{RH}$ range tested $(\mathrm{RH}=80-87 \%)$. To translate our measurements of hygroscopicity over a specific range of RHs into their water uptake ability at any $\mathrm{RH}<100 \%$ and into their ability to act as cloud condensation nuclei (CCN) at $\mathrm{RH}>100 \%$, we relied on the hygroscopicity parameter $\kappa$, developed by Petters and Kreidenweis. We retrieved $\kappa=0.22 \pm 0.12$ for the early Earth aerosol, which indicates that the humidified aerosol $(\mathrm{RH}<100 \%)$ could have contributed to a larger antigreenhouse effect on the early Earth atmosphere than previously modeled with dry aerosol. Such effects would have been of significance in regions where the humidity was larger than $50 \%$, because such high humidities are needed for significant amounts of water to be on the aerosol. Additionally, Earth organic aerosol particles could have activated into CCN at reasonable-and even low-water-vapor supersaturations $(\mathrm{RH}>100 \%)$. In regions where the haze was dominant, it is expected that low particle concentrations, once activated into cloud droplets, would have created short-lived, optically thin clouds. Such clouds, if predominant on early Earth, would have had a lower albedo than clouds today, thereby warming the planet relative to current-day clouds. Key Words: Archean-Early Earth-Organic haze-Tholin. Astrobiology 11, 135-149.
\end{abstract}

\section{Introduction}

A RCHEAN EARTH would seem an alien and hostile planet to most current-day terrestrial life. A greater fraction of early Earth may have been covered with water than currentday Earth because continents have formed slowly (Collerson and Kamber, 1999; Rosing et al., 2010), though the continental area as a function of time is poorly constrained. Massindependent isotopic signatures of sulfur from sulfide and sulfate (Farquhar et al., 2000), studies of reduced and oxidized iron and uranium minerals (Cloud, 1972), and microfossil and paleosol records (Walker, 1983) indicate that atmospheric oxygen was virtually absent in the atmosphere before 2.45 billion years ago. An anoxic atmosphere is incapable of generating an ozone layer, which shields life from lethal ultraviolet (UV) radiation in the present atmosphere. A nearglobal orange-brown organic haze, much like that found on current-day Titan, may have obscured the sky. It has been thought that the haze would create a significant antigreenhouse effect and cool Earth (Pavlov et al., 2001b; Trainer et al., 2006; Domagal-Goldman et al., 2008; Haqq-Misra et al., 2008). However, Wolf and Toon (2010) suggested that this haze may have been composed of fractal particles. Such particles form an effective UV shield that allows greenhouse gases such as ammonia $\left(\mathrm{NH}_{3}\right)$ to accumulate, while creating a smaller cooling effect than previously thought. The Sun, too, was a very different entity 2.8 billion years ago. Based on observations of other Sun-like systems, UV radiation from the Sun may have been significantly higher than that of the present (Dorren and Guinan, 1994). Due to the typical progression

\footnotetext{
${ }^{1}$ Department of Atmospheric and Oceanic Sciences, University of Colorado, Boulder, Colorado.

${ }^{2}$ Cooperative Institute for Research in the Environmental Sciences, University of Colorado, Boulder, Colorado.

${ }^{3}$ Division of Geological and Planetary Sciences, California Institute of Technology, Pasadena, California.

${ }^{4}$ Laboratory for Atmospheric and Space Physics, University of Colorado, Boulder, Colorado.

${ }^{5}$ Department of Chemistry and Biochemistry, University of Colorado, Boulder, Colorado.

*Present Address: Department of Chemistry, The Pennsylvania State University, University Park, Pennsylvania.
} 
expected of a main sequence star, the Sun has become more luminous as it has aged; 2.8 billion years ago it had $80 \%$ of the luminosity that it has today (Newman and Rood, 1977; Gough, 1981).

A simple radiative balance calculation indicates that the limited amount of solar radiation received by early Earth would have resulted in a frozen planet if the atmosphere had the same greenhouse effect as it has today (Sagan and Mullen, 1972; Sagan and Chyba, 1997). Yet studies of uranium, lead, and oxygen isotopes in ancient zircons (Mojzsis et al., 2001; Wilde et al., 2001) have indicated the presence of ubiquitous liquid water over 4 billion years ago. There is also ample fossil evidence that life, which is presumably reliant on liquid water, existed throughout the Archean (Knoll and Barghoorn, 1977; Walsh, 1992; Schopf et al., 2007). One solution to this so-called "faint young Sun paradox" is the presence of larger than current-day concentrations of greenhouse gases. From paleosol record constraints, it is believed that 2.8 billion years ago carbon dioxide $\left(\mathrm{CO}_{2}\right)$ was present in concentrations approximately 20 to no more than 100 times higher than concentrations in the present-day atmosphere (Rye et al., 1995; Sheldon, 2006). However, recent studies of banded iron formations suggest that $\mathrm{CO}_{2}$ concentrations were no more than 3 times higher than those of the present (Rosing et al., 2010). Despite the discrepancies in the geological data regarding Archean $\mathrm{CO}_{2}$ concentrations, one fact remains clear: according to models, if $\mathrm{CO}_{2}$ were the only greenhouse gas, even the upper limit of $\mathrm{CO}_{2}$ concentrations suggested by paleosol data would not have provided enough warming to offset the faint young Sun (Pavlov et al., 2000; Haqq-Misra et al., 2008). Increased concentration of atmospheric methane $\left(\mathrm{CH}_{4}\right)$ has been suggested as an additional source of greenhouse warming. During the Archean, $\mathrm{CH}_{4}$ may have existed in higher concentrations than those of the present day due to methanogenic bacteria on early Earth and the relatively long lifetime for $\mathrm{CH}_{4}$ in an anoxic atmosphere (Haqq-Misra et al., 2008). Models of early Earth 2.8 billion years ago have indicated that $<0.03$ bar $\mathrm{CO}_{2}$ and a mixing ratio of at least $10^{-3} \mathrm{CH}_{4}$ in a nitrogen $\left(\mathrm{N}_{2}\right)^{-}$ based atmosphere could have provided enough warming to boost the global average surface temperature above $273 \mathrm{~K}$ (Haqq-Misra et al., 2008). When the radiative effects of spherical organic particles are included in the models, however, the warming is offset by the antigreenhouse effect of the haze, and the paradox persists (Haqq-Misra et al., 2008). More recently, two new solutions to the problem have been suggested. Rosing et al. (2010) suggested that, despite their new greenhouse-restrictive constraint on $\mathrm{CO}_{2}$ levels, Earth could have stayed warm because the surface albedo would have been less than it is at present due to the smaller continental area. They also suggested that clouds would have had lower albedo because, with fewer cloud condensation nuclei $(\mathrm{CCN})$, the droplets would have been larger. These two effects could have maintained the Earth above freezing. Alternatively, the fractal organic aerosols suggested by Wolf and Toon (2010) may have provided a UV shield, which would have allowed $\mathrm{NH}_{3}$ to build up to 1-10 ppmv. Such levels could also keep Earth above freezing even with $\mathrm{CO}_{2}$ and $\mathrm{CH}_{4}$ at only 1000 ppmv levels.

Titan, a moon of Saturn, may act as an analogue to early Earth because its stratosphere is mostly $\mathrm{N}_{2}$ with $1.5 \%$ $\mathrm{CH}_{4}$ (Flasar et al., 2005; Niemann et al., 2005). A ubiquitous organic haze is formed from the photolysis and electrondissociation of $\mathrm{CH}_{4}$ and $\mathrm{N}_{2}$. When $\mathrm{CO}_{2}$ is added to analog atmospheres-either in the laboratory or in photochemical models - a haze forms from a gas mixture with a ratio of $\mathrm{CH}_{4} / \mathrm{CO}_{2}=0.1$ or higher (Domagal-Goldman et al., 2008; DeWitt et al., 2009). On Titan, the direct effect of the haze, which is to scatter and absorb sunlight, lowers the surface temperature on Titan by approximately $10 \%$ or $9 \mathrm{~K}$, compared to a scenario without the haze (McKay et al., 1991). A ubiquitous haze on early Earth would have had profound consequences on climate in terms of both its direct and indirect effects. Several laboratory and modeling studies have investigated the direct effect of possible early Earth aerosol (Khare et al., 1984; Haqq-Misra et al., 2008; Wolf and Toon, 2010), though none have investigated how humidified aerosols would have altered the direct effect on early Earth.

The effects of early Earth aerosol on cloud radiative properties, termed the indirect effect of the aerosol, have not been previously investigated in any laboratory study nor explicitly explored by models. Yet, there are compelling reasons to investigate the cloud-forming ability of these aerosol particles. First, the haze layer formed by these aerosol particles would likely have been nearly global in extent (Wolf and Toon, 2010). Second, many of the sources of CCN in our present-day atmosphere would not have existed, or would have been greatly reduced, in the early Earth atmosphere. Most CCN on current-day Earth are sulfates, which should have been rare on early Earth, or sea salt aerosol, which dominate in the marine boundary layer but usually exist no more than $2 \mathrm{~km}$ in altitude (Seinfeld and Pandis, 1998). Therefore, an organic aerosol haze, generated from UV photolysis of $\mathrm{CH}_{4}$, may have dominated the $\mathrm{CCN}$ in some regions of the Archean atmosphere. Specifically, the lack of other CCN sources would have been due to the absence of oxygen, which precludes most current-day natural biogenic and anthropogenic aerosols, and the lack of landmass, which supplies dust aerosol to the current-day atmosphere. Typical CCN concentrations in our current atmosphere are on the order of $100-1000 \mathrm{~cm}^{-3}$, depending upon whether the air mass is maritime or continental (Rogers and Yau, 1996). Estimates of non-anthropogenic or "natural" concentrations over the current-day oceans range from $50-200 \mathrm{CCN} \mathrm{cm}^{-3}$, due largely to products of biological activity and inorganics (Andreae and Rosenfeld, 2008). In the most remote areas of the present world, where anthropogenic and oxygen-reliant biogenic aerosol influences are minimized-perhaps reminiscent of aerosol concentrations on early Earth-typical concentrations are only a few tens per cubic centimeter (Andreae and Rosenfeld, 2008). Kump and Pollard (2008) showed that fewer $\mathrm{CCN}$ during the Cretaceous may have decreased cloud coverage and, hence, decreased Earth's effective albedo, enough to warm the planet significantly. Recently, Rosing et al. (2010) modeled the effects of fewer CCN during the Archean than at present and showed that the resultant planetary albedo would be low enough to provide enough warming to offset the faint young Sun. Rondanelli and Lindzen (2010) showed that increased cirrus clouds in the tropics could have offset a faint young Sun but mentioned no mechanism for their formation. Recent work by Goldblatt and Zahnle (2010) pointed out that a better understanding of the mechanisms by which early Earth 
clouds formed is needed before the role clouds played in radiative forcing on early Earth can be properly constrained.

Investigations into the hygroscopicity and ability of early Earth analog aerosols to serve as $\mathrm{CCN}$ are especially compelling projects, given the important role humidified aerosols and clouds must have played in both the radiative balance and hydrological cycle of our early planet. The present study is the first to report hygroscopicity measurements of an early Earth analog aerosol. From these measurements, we have calculated how the aerosol will take up water at any relative humidity (RH) (above or below 100\%), which thus allowed us to estimate the humidified aerosol's inferred direct (i.e., antigreenhouse effect) and indirect (i.e., CCN ability) effects. We measured the hygroscopicity of a Titan analog aerosol for comparison.

\section{Experimental Methods}

A tandem cavity ringdown aerosol extinction spectrometer (CRD-AES) was used to measure the optical growth factor, $f(\mathrm{RH})$, of early Earth and Titan analog aerosol for a range of particle diameters. The optical growth is defined as

$$
f(\mathrm{RH})=\frac{b_{\mathrm{ext}}^{\mathrm{wet}}}{b_{\mathrm{ext}}^{\mathrm{dry}}}
$$

where $b_{\text {ext }}^{\text {wet }}$ and $b_{\text {ext }}^{\text {dry }}$ are the extinction coefficients $\left(\mathrm{cm}^{-1}\right)$ measured under humidified and dry conditions, respectively. A schematic of the experimental setup is shown in Fig. 1.

\subsection{Description of aerosol generation}

The hygroscopicity of both early Earth and Titan analog aerosols were studied. The early Earth analog aerosol was produced by UV photolysis of an early Earth atmospheric gas mixture of $0.1 \%$ ultrahigh-purity $\mathrm{CH}_{4}$ and $0.1 \%$ research-

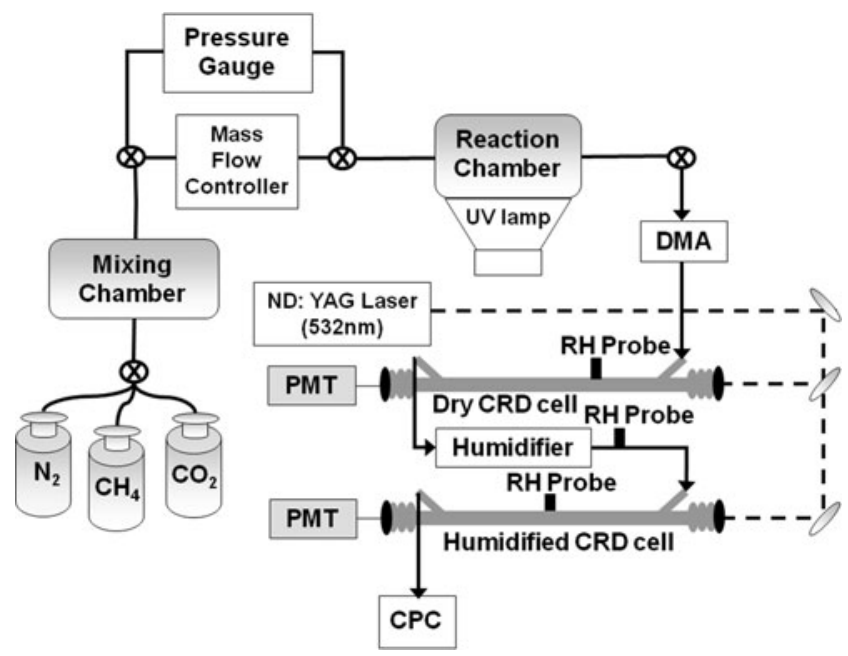

FIG. 1. Schematic of aerosol generation and the humidified tandem cavity ringdown aerosol extinction system. Abbreviations are as follows: CPC, condensation particle counter; CRD, cavity ringdown aerosol extinction spectrometer; DMA, differential mobility analyzer; $\mathrm{RH}$, relative humidity; PMT, photomultiplier tube. grade $\mathrm{CO}_{2}$ with an ultrahigh-purity $\mathrm{N}_{2}$ background. This mixture has a $\mathrm{C} / \mathrm{O}$ ratio of 1 and is considered to be a plausible early Earth analog atmosphere, in terms of both the absolute concentrations of $\mathrm{CH}_{4}$ and $\mathrm{CO}_{2}$ and $\mathrm{C} / \mathrm{O}$ ratio (Pavlov et al., 2000; Haqq-Misra et al., 2008). The $\mathrm{CO}_{2}$ concentrations, however, are a thousand times larger than the new constraints based on banded iron formations (Rosing et al., 2010).

The Titan analog aerosol was generated by the photolysis of a mixture of $0.1 \%$ ultrahigh-purity $\mathrm{CH}_{4}$ in an ultrahighpurity $\mathrm{N}_{2}$ background. Past work has shown that photolysis of this gas mixture results in aerosols of similar composition to photolysis of $2 \% \mathrm{CH}_{4}$ in $\mathrm{N}_{2}$, similar to conditions on Titan (Trainer et al., 2006). Also, because the Titan analogue has an identical mixing ratio of $\mathrm{CH}_{4}$ to our terrestrial analogue, it can provide an interesting comparison to the early Earth analogue. From previous studies in our laboratory (Trainer et al., 2006), we know that the early Earth analog aerosol generated from the early Earth gas mixture has several oxygenated species incorporated into it, which the Titan analogue lacks. Using analog gas mixtures with identical mixing ratios of $\mathrm{CH}_{4}$ illustrates the impact on hygroscopicity of including an oxygenated species in an analog gas mixture. Both analog gas mixtures used in this study were chosen for optimal aerosol production with regard to the $\mathrm{CH}_{4} / \mathrm{N}_{2}$ ratio for the Titan aerosol and the $\mathrm{C} / \mathrm{O}$ ratio for the early Earth aerosol. These analog gas mixtures, therefore, provide the maximum possible signal for our experiments.

Images of the generated aerosols were obtained through tapping-mode atomic force microscopy on a hydrophilic silica substrate $\left(\mathrm{SiO}_{x} / \mathrm{Si}(100)\right)$ and are shown in Fig. 2. The aerosols in both panels range from tens of nanometers in diameter to roughly $100 \mathrm{~nm}$. This particle size is consistent with both previous work in this laboratory and observations of Titan haze (Tomasko et al., 2005, 2008). In both images in Fig. 2, the analog aerosols appear spherical, which is in agreement with previous work that used other techniques to evaluate sphericity of our analog aerosols (Trainer et al., 2006). The spherical shape of the aerosols allows them to be treated as spherical Mie scatterers. The complex refractive indices of both these aerosols, which is necessary for analyzing the optical growth results at $\lambda=532 \mathrm{~nm}$, were determined previously in Hasenkopf et al. (2010). Our method of aerosol generation was described in greater detail by Hasenkopf et al. (2010) and Trainer et al. (2006).

\subsection{Description of $\mathrm{f}(R H)$ experiments}

After the aerosol exited the UV formation chamber, the aerosol flow rate was increased to a total of 300 standard cubic centimeters per minute $(\mathrm{sccm})$ by adding a dilution flow of pre-purified $\mathrm{N}_{2}$. The flow of dry, polydisperse aerosol then entered a differential mobility analyzer (TSI Electrostatic Classifier Model 3080, DMA), where it was surrounded by a sheath flow of $1500 \mathrm{sccm}$ of dry $\mathrm{N}_{2}$. The DMA was used to size select the particles by their electrostatic mobility. The aerosol exiting the DMA at a given voltage was dominated by a monodisperse population of single-sized particles but also included monodisperse populations of more highly charged particles of larger sizes. For our experimental setup, the number of doubly charged particles was small but significant enough to affect the 

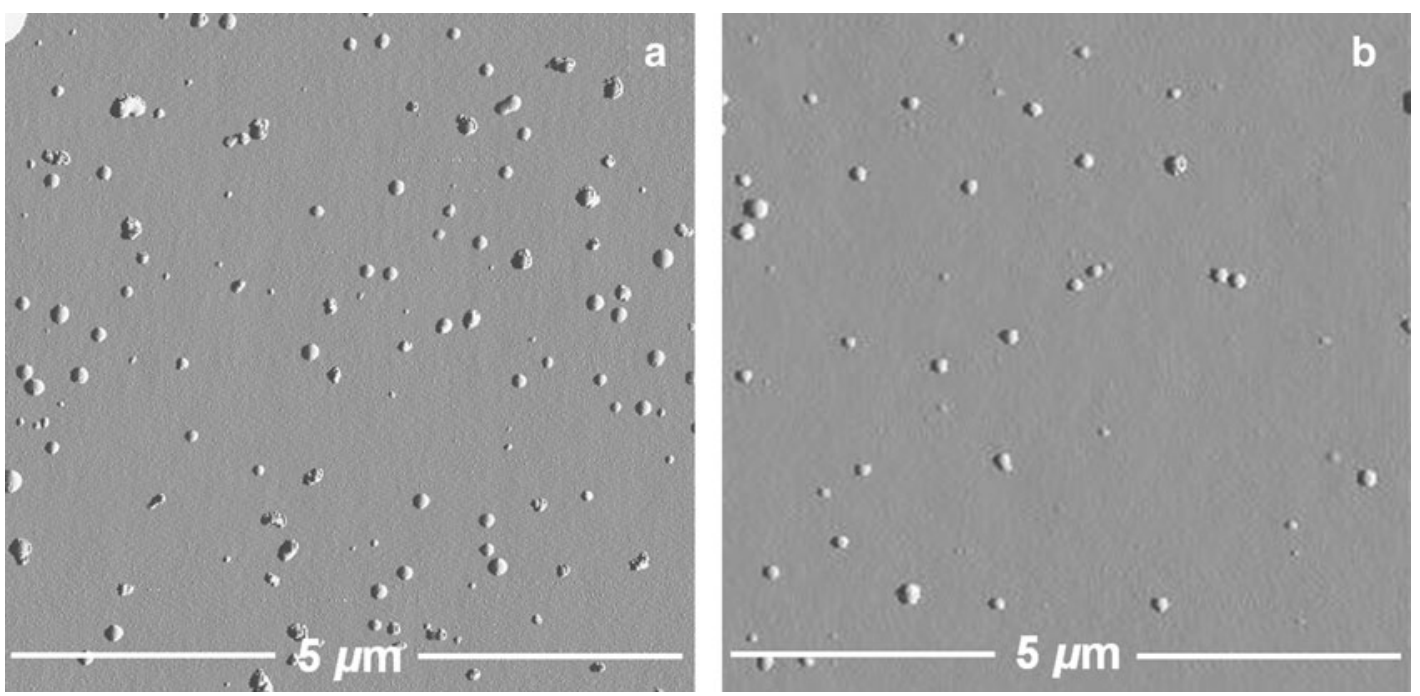

FIG. 2. Atomic force microscope images of (a) early Earth and (b) Titan analog aerosols. (a) The early Earth analog aerosol was generated by UV photolysis of a $0.1 \% \mathrm{CH}_{4}$ and $0.1 \% \mathrm{CO}_{2}$ in $\mathrm{N}_{2}$ analog atmosphere on silica substrate. (b) The Titan analog aerosol was generated by UV photolysis of a $0.1 \% \mathrm{CH}_{4}$ in $\mathrm{N}_{2}$ analog atmosphere and collected on a silica substrate.

extinction coefficient measured by the CRD-AES. The number of particles at higher charges than +2 is negligible.

To account for the doubly charged particles' effect on extinction, an optical effective diameter $D_{\text {eff }}$ was employed, as has been done in previous optical growth studies (Garland et al., 2007; Beaver et al., 2008). The effective diameter $D_{\text {eff }}$ is the equivalent diameter of identically sized particles that yield the same extinction coefficient $b_{\text {ext }}$ for the same concentration $C$ (particles $\mathrm{cm}^{-3}$ ) and have the same refractive indices as the polydisperse population. To calculate $D_{\text {eff }}$ for a given selected particle size, the effective extinction cross section $\sigma_{\text {ext }}^{\text {eff }}\left(\mathrm{cm}^{2}\right.$ particle $\left.{ }^{-1}\right)$ is calculated by dividing the measured dry $b_{\text {ext }}$ of the particles by $C$. Then, by using $\sigma_{\text {ext }}^{\text {eff }}$ Mie theory for spherical particles, and the real and imaginary parts of the refractive index of the particle, the corresponding $D_{\text {eff }}$ is calculated. The average difference between $D_{\text {eff }}$ and the diameter selected by the DMA is $6 \mathrm{~nm}$. In the results and implications sections, $D_{\text {eff }}$ and dry diameter $D_{\text {dry }}$ are used interchangeably.

After the aerosol particles were size-selected in the DMA, they entered the tandem cavity ringdown aerosol extinction spectrometers with humidity control. The details of the CRDAES have been described previously in Baynard et al. (2007), Garland et al. (2007), and Beaver et al. (2008) and thus are only briefly described here. The body of each CRD-AES cell is a $0.85 \mathrm{~m}$ stainless steel tube. Highly reflective (reflectivity $>99.998 \%$ ) mirrors (Advanced Thin Films) are mounted on both ends of the tube. The second harmonic, $\lambda=532 \mathrm{~nm}$, from a neodymium-doped yttrium aluminum garnet laser (Nd:YAG, Big Sky Laser Technologies, Quantel USA), is pulsed into the cavity and reflects back and forth many times on the mirrors. In a cell with only the background gas (devoid of particles) and over a characteristic timescale $\tau_{0}$, the intensity of the light falls to $1 / e$ of its initial intensity. A typical $\tau_{0}$ for our system was $100 \mu \mathrm{s}$, which corresponds to an effective pathlength of $30 \mathrm{~km}$. When the cell was filled with aerosol, the ringdown time was decreased to a new ringdown time, $\tau$. By comparing the two ringdown times, a measure of the extinction coefficient $b_{\text {ext }}$ can be made (Pettersson et al., 2004):

$$
b_{\mathrm{ext}}=\frac{R_{\mathrm{L}}}{c}\left(\frac{1}{\tau}-\frac{1}{\tau_{0}}\right)
$$

where $R_{\mathrm{L}}$ is the ratio of the total cavity length $(0.85 \mathrm{~m})$ to the cavity length occupied by aerosol sample $(0.75 \mathrm{~m})$ and $c$ is the speed of light.

In the CRD-AES, the aerosol particles first travel into a CRD-AES cell, in which the extinction coefficient of the dry aerosol $(\mathrm{RH} \leq 13 \%)$, $b_{\mathrm{ext}}^{\text {dry }}$, is measured. The particles then flow into a temperature-controlled humidification cell, in which they are exposed to a higher RH. The humidification cell is a stainless steel tube lined with Nafion tubing (Accurel, Permapure), a water-vapor-permeable membrane. Liquid water is injected into the space between the stainless steel and the Nafion tubing. By varying the temperature of the liquid water inside the humidification cell, one can vary the $\mathrm{RH}$ to which the particles are exposed. After humidification, the particles flow into a second CRD-AES cell where the extinction at an elevated RH, $b_{\text {ext }}^{\text {wet }}$, is measured. The RH is monitored in both CRD-AES cells with Vaisala Humitter 50Y probes $( \pm 3 \%$ accuracy). Finally, the particles exit the humidified CRD-AES cell and enter a condensation particle counter (TSI Model 3022), where the particle concentration is measured.

Before each experiment was conducted, it was ensured that there were no particle losses between the cells and that the cells responded identically. Particles at a chosen diameter were flowed through both cells, where the $\mathrm{RH}$ was held constant and low $(\mathrm{RH}<13 \%)$. The cells are considered to have identical response when their extinctions match within error of the extinction measurements due to fluctuations in particle concentrations, which is generally within $2 \%$ of each other. The similarity of the extinction between the cells indicates that negligible particle loss has occurred and that the cells have a similar response to the particles. 


\section{Results}

\subsection{Experimental validation using ammonium sulfate}

To verify the system, we measured the $f(\mathrm{RH})$ of ammonium sulfate particles at nine diameters between 150 and $500 \mathrm{~nm}$ at $\mathrm{RH}=80 \%$. The particles were generated via atomization of a $10 \%$ ammonium sulfate-HPLC water solution. A syringe pump (Harvard Apparatus Model 70-2208) injected the solution into an atomizer (TSI Model 3076) with pre-purified $\mathrm{N}_{2}$ as the carrier gas. The aqueous particles were then flowed through several driers to ensure that dry particles entered the CRD-AES. Ammonium sulfate aerosol generation and characterization is described in more detail in Hasenkopf et al. (2010).

Figure 3 shows the results from the test case. Each $f(\mathrm{RH})$ value at a given diameter is an average of at least three data points, each data point itself an average of extinction measurements sampled every $10.3 \mathrm{~s}$ for $2 \mathrm{~min}$. Each $f(\mathrm{RH})$ value was calculated from data obtained on at least two different days for $79 \%<\mathrm{RH}<81 \%$. The error bars in Fig. 3 indicate the uncertainty in $\mathrm{RH}$ of $\pm 3 \%$. Figure 3 also compares the test case values with previous ammonium sulfate $f(\mathrm{RH})$ studies at $\mathrm{RH}=80 \%$ (Garland et al., 2007; Beaver et al., 2008) and theoretical predictions calculated from the extended Aerosol Inorganic Model (e-AIM) (http://www.aim.env .uea.ac.uk/aim/aim.php; Clegg et al., 1992, 1998; Wexler and Clegg, 2002) and Mie theory. Garland et al. (2007) used a similar technique, and Beaver et al. (2008) used the same system as this study but had different flow rates. The e-AIM is a thermodynamic model that calculates the gas and liquid phase partitioning of water in a system based on ambient temperature, $\mathrm{RH}$, and chemical composition. By using the refractive indices of water $(n=1.33$ and $k=0.000)$ and ammonium sulfate $(n=1.53$ and $k=0.000)$ and assuming volume-weighted mixing of the refractive indices, the $f(\mathrm{RH})$ for different-sized particles can be calculated with Mie theory. The Mie code we used is from Grainger et al. (2004) and is freely available (http://www.atm.ox.ac.uk/code/mie/index .html). Our test case results are in good agreement with previous studies and theoretical predictions for ammonium sulfate.

The geometric growth factor $\left(G_{f}\right)$ of ammonium sulfate at $\mathrm{RH}=80 \%$ can also be compared with other measurements in the literature. The $G_{f}$ is the ratio of the humidified particle diameter over the dry particle diameter. To convert the measured $f(\mathrm{RH})$ values to $G_{\mathrm{f}}$, Mie theory is applied. The humidified particle's extinction coefficient $b_{\text {ext }}^{\text {wet }}$, can be modeled as

$$
b_{\text {ext }}^{\text {wet }}=\frac{\pi}{4} Q_{\text {ext }}^{\text {wet }}\left(D_{\text {wet }}, n_{\text {wet }}, k_{\text {wet }}\right) D_{\text {wet }}^{2} N
$$

where $D_{\text {wet }}$ is the diameter of the wet particle, $N$ is the concentration of particles $\left(\mathrm{cm}^{-3}\right)$, and $Q_{\mathrm{ext}}^{\text {wet }}$ is the extinction efficiency of the humidified particle and is a function of the volume-weighted refractive indices, $n_{\text {wet }}$ and $k_{\text {wet }}$, of the dry particle and the water. The volume-weighted real refractive index is

$$
n_{\text {wet }}=\frac{n_{\text {dry }} D_{\text {dry }}^{3}+n_{\mathrm{H}_{2} \mathrm{O}} D_{\mathrm{H}_{2} \mathrm{O}}^{3}}{D_{\text {dry }}^{3}+D_{\mathrm{H}_{2} \mathrm{O}}^{3}}
$$

where $D_{\mathrm{H}_{2} \mathrm{O}}$ is the volume-equivalent diameter of the liquid water portion of the humidified aerosol. An analogous expression is used for $k_{\text {wet }}$. The dry size of the aerosol $D_{\text {dry }}$ is measured as described in Section 2.2, $N$ is also measured, and the complex refractive index of ammonium sulfate and water at $\lambda=532 \mathrm{~nm}$ is well established (Garland et al., 2007; Beaver et al., 2008). A range of $D_{\text {wet }}$ in $0.1 \mathrm{~nm}$ increments are put into Eq. 3, and the humidified diameter that yields the best fit to $b_{\text {ext }}^{\text {wet }}$ is used to calculate the $G_{f}$.

Table 1 shows a comparison of $G_{f}$ values at $\mathrm{RH}=80 \%$ determined from this study with several others. As with the $f(\mathrm{RH})$ measurements shown in Fig. 3, the $G_{\mathrm{f}}$ calculated from

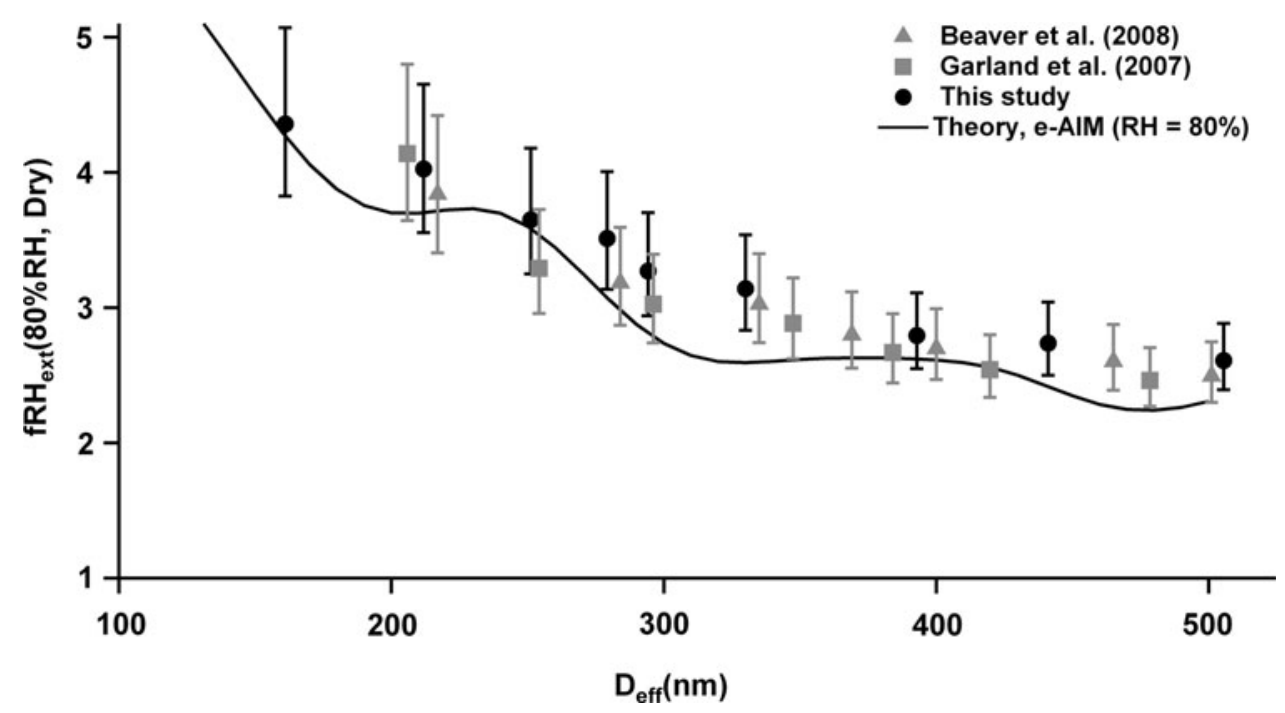

FIG. 3. $f(\mathrm{RH}=80 \%)$ of ammonium sulfate for a range of particle diameters from different studies [this study = black circles; Beaver et al. (2008)= gray triangles; and Garland et al. $(2007)=$ gray squares]. The solid black line represents the $f(\mathrm{RH})$ predicted for ammonium sulfate using e-AIM and Mie theory. The error bars represent error based on the uncertainty in the measured RH. 
Table 1. Comparison of $G_{f}$ and $\kappa$ of Titan and Early Earth Analog Aerosols, As Well As OTHER INORGANIC AND ORganic COMPOUNDS

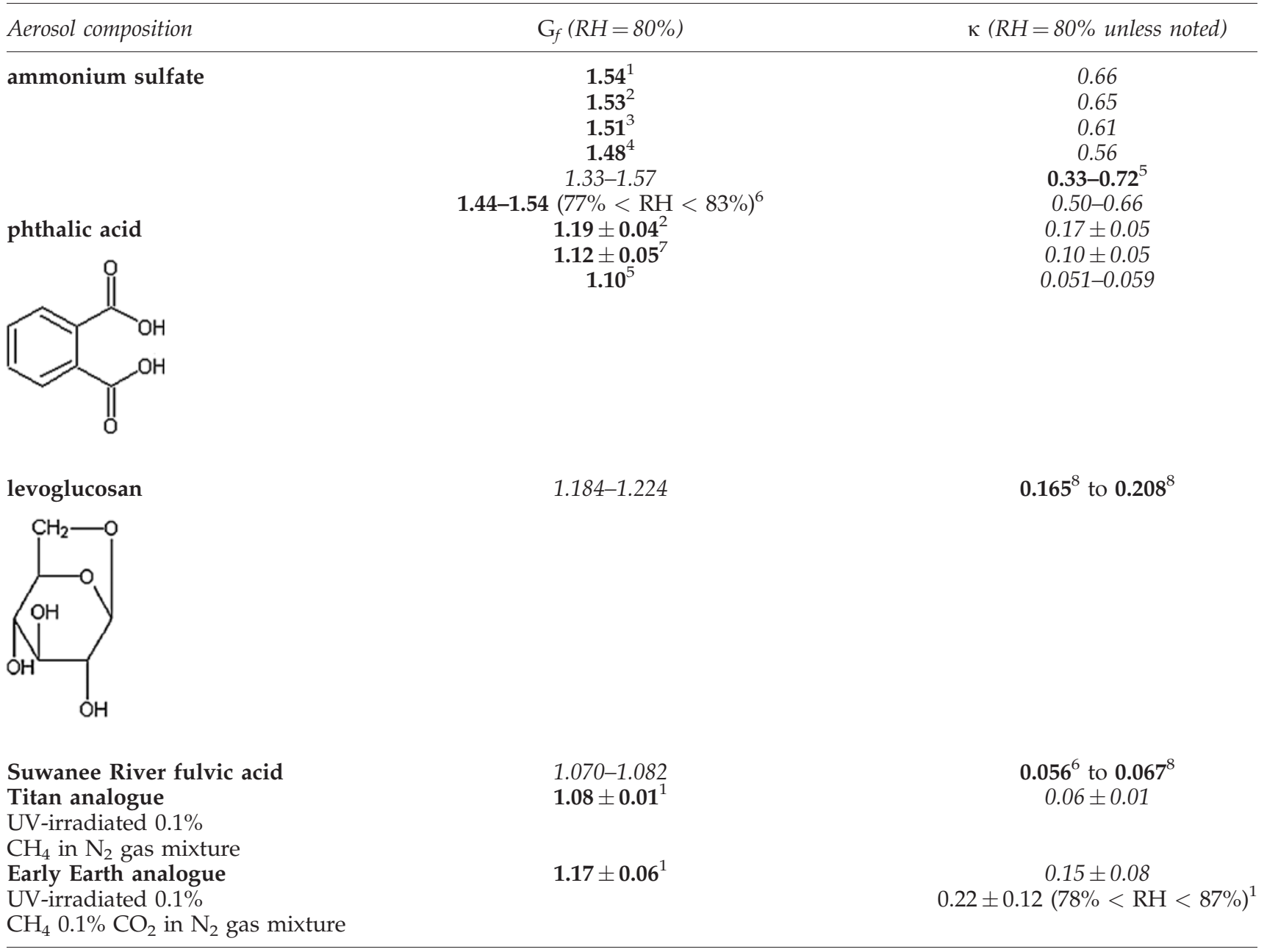

The italicized values were calculated from the boldface values in the same row.

${ }^{1}$ This work.

${ }^{2}$ Beaver et al. (2008) - growth factor is calculated from $f(\mathrm{RH}=80 \%)$ measurements.

${ }^{3}$ Garland et al. (2007)- growth factor is calculated from $f(\mathrm{RH}=80 \%)$ measurements.

${ }^{4}$ Tang (1996).

${ }^{5}$ Petters and Kreidenweis (2007) - upper and lower $\kappa$-values determined from growth factor and CCN data.

${ }^{6} \mathrm{e}-\mathrm{AIM}$ calculation (http://www.aim.env.uea.ac.uk/aim/aim.php).

${ }^{7}$ Brooks et al. (2004) - growth factor is measured from humidified tandem DMA data.

${ }^{8}$ Svenningsson et al. (2006) - growth factor is measured by humidified tandem DMA data.

this study is comparable to others that have used systems similar to the one used in this work (Garland et al., 2007; Beaver et al., 2008) and also to those that have used different techniques (Petters and Kreidenweis, 2007). Calculating $G_{f}$ for $77 \%<\mathrm{RH}<83 \%$ using the e-AIM, which corresponds to the error at $\mathrm{RH}=80 \%$ of the $\mathrm{RH}$ probes, we find that our measured $G_{f}$ falls within the calculated range.

\section{2. $\mathrm{f}(R H)$ and $\mathrm{G}_{f}$ at $R H=80 \%$ for early Earth and Titan analog aerosols}

Figure 4 shows the $f(\mathrm{RH}=80 \%)$ of early Earth and Titan analog aerosols. An $\mathrm{RH}$ of $80 \%$ was chosen to provide comparison with previous optical growth studies of ammonium sulfate and slightly soluble organics (namely, phthalic and pyromellitic acids) also performed at $\mathrm{RH}=80 \%$ (Garland et al., 2007; Beaver et al., 2008). In addition, within the detection limits of the system, it is difficult to obtain enough difference in the dry versus the humidified signal of these aerosols for studies conducted much lower than $\mathrm{RH}=80 \%$. The size range of the diameters tested was dependent upon available signal, which is affected by both aerosol concentration and the particle's optical properties. Like the ammonium sulfate data, each $f(\mathrm{RH})$ value at a given diameter is an average of at least three sets of data points, each data point itself an average of extinction measurements sampled every $10.3 \mathrm{~s}$ for $2 \mathrm{~min}$. As in the ammonium sulfate test case, each $f(\mathrm{RH})$ value was calculated from data points obtained on at least two different days for $79 \%<\mathrm{RH}<81 \%$. The error bars indicate the standard deviation among the data points used.

Both analog aerosols have $f(\mathrm{RH})>1$, exhibiting water uptake at $\mathrm{RH}=80 \%$. The $f(\mathrm{RH})$ of the early Earth analogue is 


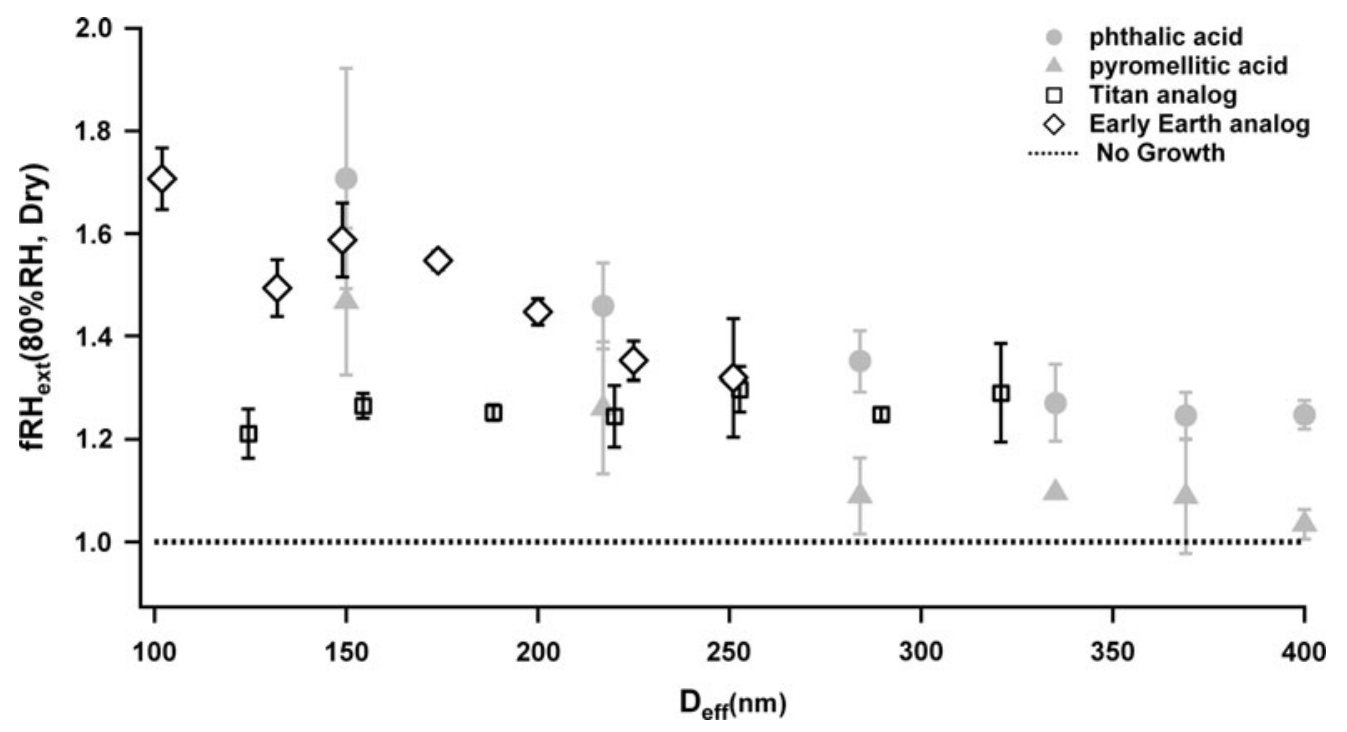

FIG. 4. Optical growth $f(\mathrm{RH})$ of early Earth and Titan analog aerosols of various particle diameters at $\mathrm{RH}=80 \%$ (this work) compared with other slightly soluble organics (Beaver et al., 2008). The dotted line at $f(\mathrm{RH})=1$ indicates no growth due to water uptake on the particles. The error bars represent the standard deviation of repeated measurements.

similar to phthalic and pyromellitic acids, both of which are aromatic dicarboxylic acids. Though the refractive indices of phthalic and pyromellitic acids are not reported in the literature, they presumably have very similar real and imaginary refractive indices, since they have similar chemical structures. The chemical structure and measured $G_{f}$ at $\mathrm{RH}=80 \%$ of phthalic acid [assuming $n=1.60$ and $k=0.000$, as done in Beaver et al. (2008)] is shown in Table 1. The similarity between phthalic and pyromellitic acids and the early Earth analog aerosol in terms of hygroscopicity is qualitatively consistent with previous chemical composition studies of the early Earth analog aerosol that identified dicarboxylic acids and aromatics in aerosol mass spectra of analog aerosol generated in an identical manner to this study (Trainer et al., 2006).

The $f(\mathrm{RH})$ versus diameter curves in Fig. 4 depend upon $G_{\mathrm{f}}$ and $Q_{\text {ext }}^{\text {wet }}$, which, as shown in Eq. 3, are dependent upon $D_{\text {wet }}$ and the refractive indices of the wet particle:

$$
f(\mathrm{RH})=\frac{b_{\mathrm{ext}}^{\text {wet }}}{b_{\mathrm{ext}}^{\text {dry }}}=\frac{Q_{\mathrm{ext}}^{\text {wet }}}{Q_{\mathrm{ext}}^{\text {dry }}} G_{\mathrm{f}}^{2}
$$

For a particle of a given composition over the range of RHs studied, $G_{f}$ is a strong function of $\mathrm{RH}$ and a very weak function of dry particle diameter for particles in the size range studied in this work. The weak dependence of $G_{f}$ on dry particle diameter is due to the negligible importance of the Kelvin effect for particles greater than $D_{\text {dry }} \sim 70 \mathrm{~nm}$ (Lewis, 2006; Gao et al., 2007). The error in $G_{\mathrm{f}}$ due to treating it as a constant with particle diameter is approximately $2 \%$ for the smallest sizes studied $\left(D_{\text {dry }}=125 \mathrm{~nm}\right)$, which is smaller than experimental uncertainties (Lewis, 2006).

The deviation of $f(\mathrm{RH})$ from a straight horizontal line in Eq. 5 is due to the $\frac{Q_{\mathrm{et}}^{\text {wet }}}{Q_{\mathrm{ext}}^{\text {dyy }}}$ term. The particles are comparable in size to the wavelength with which they are being investigated $(\lambda=532 \mathrm{~nm})$, and are therefore in the Mie size regime. At the smaller particle diameters investigated $(\pi D / \lambda<1)$, small increases in size due to water uptake and small differences between the complex refractive indices of the dry versus the wet particle can result in large changes in the ratio of the wet and dry extinction efficiencies. The impact of these small differences in wet and dry sizes and refractive indices at smaller particle diameters are evident in the shape of the $f(\mathrm{RH})$ curves for early Earth, phthalic acid, and pyromellitic acid particles. For the Titan case, the $f(\mathrm{RH})$ curve is much flatter, indicative of its lower hygroscopicity, which translates into smaller differences in the sizes of wet and dry particles. Also, the shape of Titan's $f(\mathrm{RH})$ curve is impacted by its dry refractive index $(n=1.35$ and $k=0.023)$, which is closer to that of water $(n=1.33, k=0.000)$ than that of the early Earth analogue $(n=1.81, k=0.055)$.

The $G_{f}$ at $\mathrm{RH}=80 \%$ is reported in Table 1 for early Earth and Titan analog aerosols. The $G_{f}$ reported is the average $G_{f}$ measured at all sizes, and the error reported is the standard deviation. The conversion from $f(\mathrm{RH})$ to $G_{\mathrm{f}}$ was performed in the same manner as $G_{f}$ calculations for ammonium sulfate in Section 3.1. The $G_{\mathrm{f}}$ at $\mathrm{RH}=80 \%$ for early Earth and Titan are $1.17 \pm 0.06$ and $1.08 \pm 0.01$, respectively. From chemical considerations, it is not surprising that the early Earth aerosol particles are slightly more hygroscopic than the Titan aerosol. Trainer et al. (2006) found that the early Earth analog aerosol contains significant amounts of oxygen. It is expected from theoretical considerations, laboratory studies (Kotzick and Niessner, 1999), and field campaigns (Jimenez et al., 2009) that a more oxidized version of a given organic will be more hygroscopic.

\subsection{Hygroscopicity parameter $\kappa$ at $\mathrm{RH}=80 \%$ for early Earth and Titan analog aerosols}

The geometric growth factors can be used to calculate the hygroscopicity parameter $\kappa$. This parameter describes a particle's behavior in both sub- and supersaturated conditions based on its chemical composition. The hygroscopicity parameter enables investigators to take our measurements, 
performed in subsaturated conditions at one $\mathrm{RH}$ or over a range of RHs, and calculate an analog aerosol's direct effect on the radiative balance of the early Earth atmosphere at any $\mathrm{RH}$ and also its ability to act as CCN. This parameter was first developed by Petters and Kreidenweis (2007) and can be used to express what they term as " $\kappa$-Kohler theory," which describes the RH (i.e., the saturation ratio $S$ over an aqueous solution droplet:

$$
\frac{S}{\exp \left(\frac{4 \sigma_{\mathrm{s} / \mathrm{a}} M_{w}}{R T \rho_{w} D}\right)}=\frac{D^{3}-D_{\text {dry }}^{3}}{D^{3}-D_{\text {dry }}^{3}(1-\kappa)}
$$

where $D$ is the wet droplet diameter, $D_{\text {dry }}$ is the dry diameter of the dry aerosol, $\sigma_{\mathrm{s} / \mathrm{a}}$ is the surface tension of the solution/ air interface, $M_{\mathrm{w}}$ is the molecular weight of water, $R$ is the universal gas constant, $T$ is the temperature, and $\rho_{\mathrm{w}}$ is the density of water. As Petters and Kreidenweis (2007) described, the use of the hygroscopicity parameter $\kappa$ circumvents the need to define aerosol properties such as density, molecular weight, or dissociation constants. For reference, pure water has a $\kappa$-value of 0 , and an extremely hygroscopic compound such as sodium chloride has a $\kappa$-value of 1.4 (Petters and Kreidenweis, 2007). For our calculations, we assume $\sigma_{\mathrm{s} / \mathrm{a}}=0.072 \mathrm{~J} \mathrm{~m}^{-2}$, which is the surface tension of water. Though the actual $\sigma_{\mathrm{s} / \mathrm{a}}$ for the organic analog aerosolwater mixture is unknown, it has been shown that for subsaturated regimes of $\mathrm{RH}<95 \%$, hygroscopic growth is "almost insensitive to $\sigma_{\mathrm{s} / \mathrm{a}}$ " (Wex et al., 2008), based on fundamental properties of the Kohler equation. For a given $f(\mathrm{RH})$ measurement, the $\mathrm{RH}$ is controlled, $D_{\text {dry }}$ is known, $D$ is calculated as described in Sections 3.1 and 3.2, and the temperature at which all experiments were conducted was $293 \mathrm{~K}$. The only unknown in Eq. 6 is $\kappa$, which can then be calculated.

In Table 1, we have listed the calculated $\kappa$-values for the early Earth and Titan analog aerosols and compared them to other compounds. Also, Table 1 includes $\kappa$ calculated for our ammonium sulfate $f(\mathrm{RH})$ measurements, which, like the $f(\mathrm{RH})$ and $G_{\mathrm{f}}$ measurements, agree with other experimental studies and theory. For all compounds, the italicized values are calculated from the boldface values in the same row. For the early Earth analog aerosol, we calculate $\kappa=0.15 \pm 0.08$ at $\mathrm{RH}=80 \%$, and for Titan $\kappa=0.06 \pm 0.01$ at $\mathrm{RH}=80 \%$. As expected from the growth factor values reported in Section 3.2 , the early Earth $\kappa$-value is higher than the Titan value. The early Earth analog aerosol has a comparable $\kappa$-value to levoglucosan, an oxidized organic that is a product of wood combustion. Interestingly, $\kappa \sim 0.1$ is a typical range of values found for secondary organic aerosol generated in the laboratory that is designed to represent aerosol found in the current-day atmosphere (Prenni et al., 2007; Wex et al., 2009).

\section{4. $\mathrm{f}(R H)$ and $\mathrm{\kappa}$ of early Earth aerosols over a range of relative humidities}

Petters and Kreidenweis (2007) showed experimentally that $\kappa$ derived from hygroscopic data obtained in a subsaturated regime for many organic and inorganic aerosols are within experimental uncertainties of those derived from $\kappa$ obtained from a supersaturated regime. However, several other studies have found that $\kappa$ is not constant in present-day Earth secondary organic aerosol particles with increasing $\mathrm{RH}$ in both the subsaturated and supersaturated regimes (Hartz et al., 2005; VanReken et al., 2005; King et al., 2007; Prenni et al., 2007; Duplissy et al., 2008; Engelhart et al., 2008; Wex et al., 2009). We assessed the constancy of $\kappa$ for our early Earth analog aerosol by measuring $\kappa$ over a range of subsaturated conditions. Assessing the constancy of $\kappa$ allowed us to assess the CCN ability of the early Earth analog aerosol in the Archean atmosphere based on our results obtained in subsaturated conditions.

Figure 5 shows the 74 individual $f(\mathrm{RH})$ measurements for various particle sizes from $\mathrm{RH}=78-87 \%$. Each $f(\mathrm{RH})$ value at a given diameter is one data point that represents an average of extinction measurements sampled every $10.3 \mathrm{~s}$ for $2 \mathrm{~min}$.

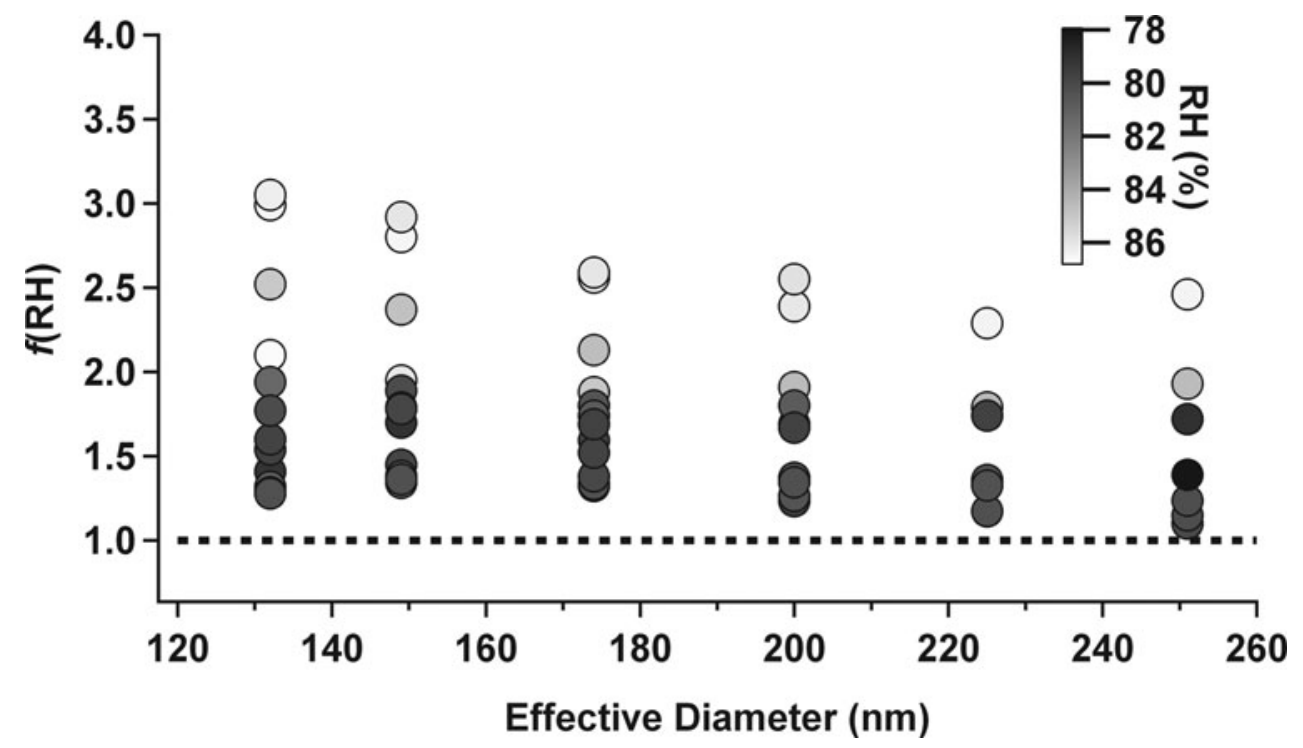

FIG. 5. Optical growth $f(\mathrm{RH})$ of early Earth analog aerosols of various particle diameters over a range of relative humidities $(\mathrm{RH}=78-87 \%)$. 
As expected, $f(\mathrm{RH})$ decreases with increasing particle size and increases at a given size as RH increases. At each of the 74 points in Fig. 5, a $\kappa$-value can be calculated. The average $\kappa$ for the entire range and all early Earth analog diameters is $0.22 \pm 0.12$.

Figure 6 shows a plot of $\kappa$ versus RH. From Fig. 6, there appears to be a dependence of $\kappa$ on RH. The RH dependence of $\kappa$ is quantitatively assessed by calculating the statistical significance of the correlation with Spearman's rank correlation coefficient $\rho$. A value of $\rho=+0.69$ is found, which, for 74 data points, indicates a very significant correlation (>99.9\% confidence) between $\kappa$ and RH. Again, this dependence and the direction of this dependence-increasing $\kappa$ with $\mathrm{RH}$-appears to be common in the literature. A study on three types of secondary organic aerosol by Wex et al. (2009) showed an order of magnitude increase in $\kappa$ from $\mathrm{RH}=80 \%$ to $\mathrm{RH}=99.6 \%$. Also, the error in the average $\kappa$ value for the early Earth analog aerosol over the humidified range is larger than the error obtained at $\mathrm{RH}=80 \%$. This difference can be explained by this dependence of $\kappa$ on $\mathrm{RH}$. Given the trend in increasing $\kappa$ with $\mathrm{RH}$ and similar results in secondary organic aerosol in other studies, our reported early Earth $\kappa$-value likely represents an underestimate of the true CCN ability of this early Earth analog aerosol. Additionally, the statistical significance of the correlation between particle diameter and $\mathrm{RH}$ was tested. The correlation between these two variables was found to be statistically insignificant ( $<95 \%$ confidence) with a $\rho=-0.10$ for 74 data points.

\section{Implications}

\subsection{Direct effect of humidified aerosol}

We estimated the radiative impact of the humidified organic aerosol by using the calculated hygroscopicity parameter $\kappa$ to compare the globally averaged direct aerosol radiative forcing of the humidified aerosol $\Delta F_{\text {hum }}$ to that of the dry aerosol $\Delta F_{\text {dry }}$ (both in units of $\mathrm{W} \mathrm{m}^{-2}$ ). The globally averaged solar direct radiative forcing $\Delta F$ of an absorbing aerosol layer is proportional to

$$
\Delta F \propto-\left[(1-a)^{2} \beta \tau_{\mathrm{sca}}-2 a \tau_{\mathrm{abs}}\right]
$$

where $a$ is the albedo of the underlying surface, $\beta$ is the fraction of the radiation scattered into the upper hemisphere, and $\tau_{\text {sca }}$ and $\tau_{\text {abs }}$ are the optical depths of the aerosol layer due to scattering and absorption, respectively (Chylek and Wong, 1995). To calculate the absolute magnitude of $\Delta F$, a prefactor including the solar constant, transmittance of the atmosphere above the aerosol layer, and fraction of the sky covered by clouds would need to be included (Chylek and Wong, 1995). Because all these values in the prefactor are not well constrained and, for the same sky conditions, do not explicitly change for aerosol of different optical properties (corresponding to aerosol exposed to different RHs), we did not include them in our calculations. To compare $\Delta F_{\text {hum }}$ and $\Delta F_{\text {dry }}$ for two otherwise identical aerosol layers of particle concentration $C$ and thickness $l$, we took the ratio of the two and substituted $\tau=\sigma \mathrm{Cl}$, where $\sigma$ is the scattering or absorption cross section of the particle $\left(\mathrm{cm}^{2}\right.$ particle $\left.{ }^{-1}\right)$, as indicated by subscript:

$$
R_{\Delta F}=\frac{\Delta F_{\text {hum }}}{\Delta F_{\text {dry }}}=\frac{(1-a)^{2} \beta_{\text {hum }} \sigma_{\text {sca }- \text { hum }}-2 a \sigma_{\text {abs }- \text { hum }}}{(1-a)^{2} \beta_{\text {dry }} \sigma_{\text {sca }- \text { dry }}-2 a \sigma_{\text {abs }- \text { dry }}}
$$

For the calculations that follow, $a$ is assumed to be 0.22 , the planetary albedo estimated for an atmosphere of $10^{-3}$ bar $\mathrm{CO}_{2}$ and $0.1 \% \mathrm{CH}_{4}$ (Haqq-Misra et al., 2008). The upscattering fraction $\beta$ is approximated as $\beta=(1-g / 2) / 2$ (Sagan and Pollack, 1967; Chylek and Wong, 1995), where $g$ is the asymmetry parameter. For the size range of particles considered, $\beta$ corresponds to the upscattered fraction for an average $60^{\circ}$ solar zenith angle (Wiscombe and Grams, 1976). The optical cross sections $\sigma_{\mathrm{sca}}$ and $\sigma_{\mathrm{abs}}$ are functions of $\mathrm{RH}$

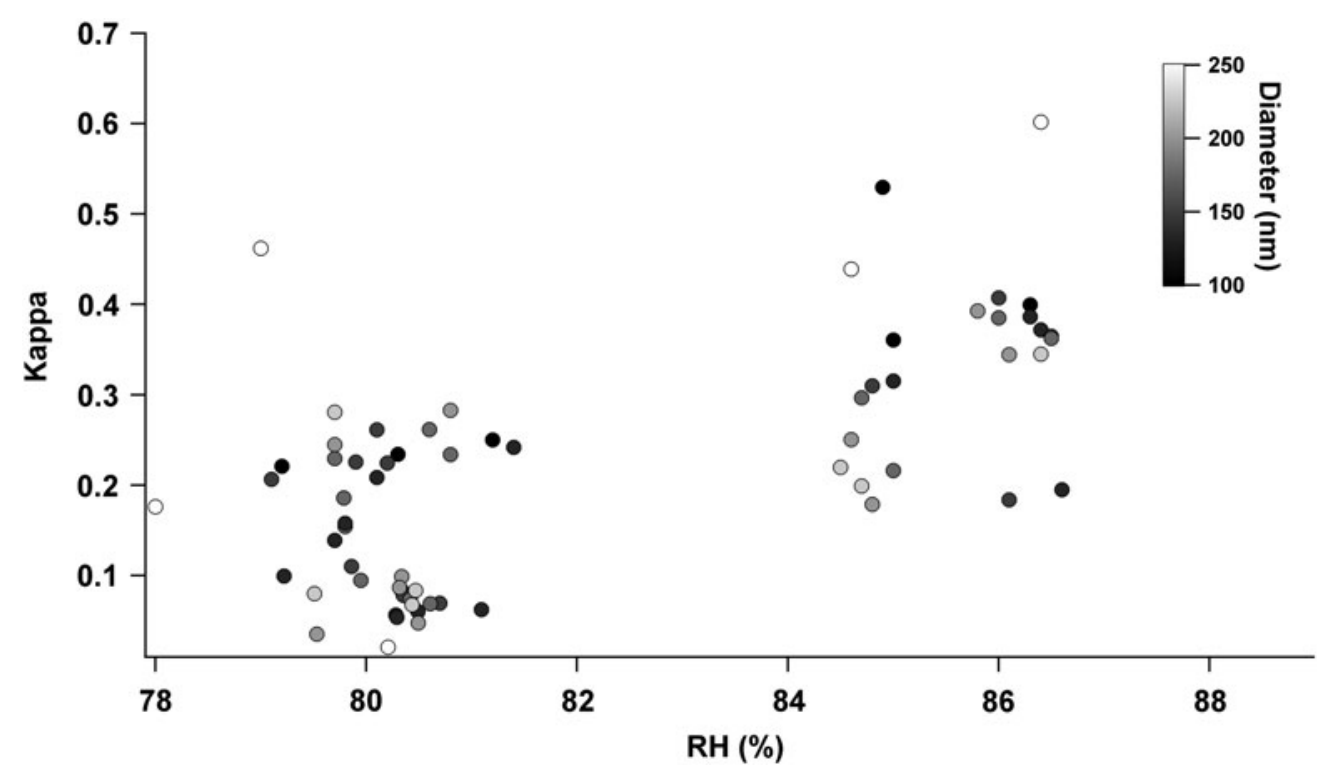

FIG. 6. $\kappa$ as a function of RH for early Earth analog aerosols. A positive and statistically significant ( $>99.9 \%$ confidence) correlation between $\kappa$ and RH is found using a Spearman's rank correlation coefficient analysis. 
and therefore of $\kappa$, which dictates the humidified aerosol's size and volume-weighted refractive index. The humidified aerosol size (or $G_{\mathrm{f}}$ ) is determined by inputting our measured $\kappa$-value into Eq. 6. Once $G_{f}$ is calculated, the volumeweighted refractive index of the humidified aerosol can be input into a Mie code assuming spherical particles, in which the optical cross sections and $g$ (and therefore $\beta$ ) are determined as a function of $\mathrm{RH}$.

Figure 7 (a) shows the term proportional to $\Delta F$ (given in Eq. 7) over a range of particle diameters and RHs. This calculation assumes the hygroscopicity parameter measured in this work and the optical properties of the dry early Earth analog aerosol measured by Hasenkopf et al. (2010). For dry $(\mathrm{RH}=0 \%)$ particles in the size range of $115 \mathrm{~nm}>D>$ $665 \mathrm{~nm}$, a net cooling effect is induced by the aerosol. Increasing the RH of the particles in this size range further increases their cooling effect. Because of the significant imaginary refractive index of the early Earth analog aerosols, at dry diameters larger than $665 \mathrm{~nm}$, a net warming effect is induced by the aerosol. This heating effect is mitigated as particles are exposed to higher RHs.
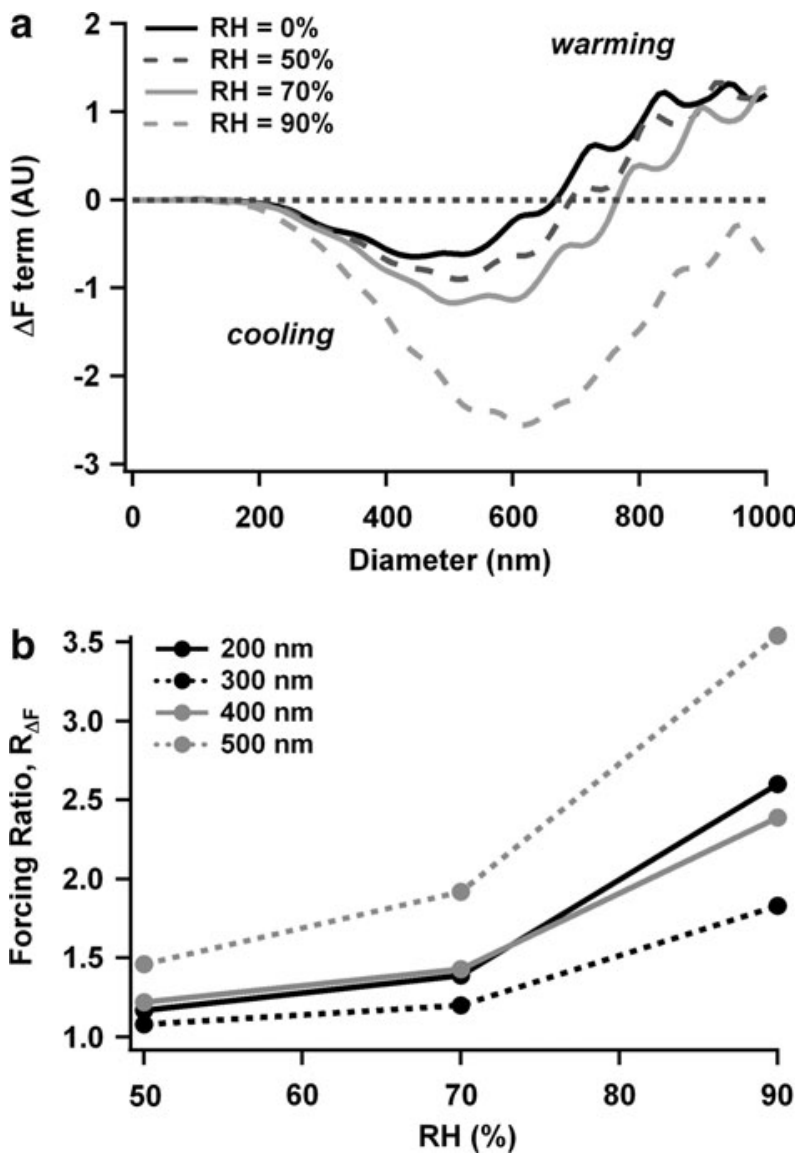

FIG. 7. (a) The term proportional to the net forcing of an early Earth aerosol layer, $\Delta F$, calculated over a range of diameters and for dry and humidified particles, assuming the optical properties of early Earth analog aerosol measured in Hasenkopf et al. (2010). The sign of $\Delta F$ indicates heating (positive) or cooling (negative). (b) The ratio of the humidified forcing to the dry forcing: $R_{\Delta F}=\Delta F_{\text {hum }} / \Delta F_{\text {dry }}$ calculated over a range of RHs at various particle diameters.
Figure $7(\mathrm{~b})$ shows the ratio, $R_{\Delta F}$, of the $\Delta F$ term of humidified haze aerosol to the $\Delta F$ term of dry haze aerosol as a function of RH for particles of diameters $200-500 \mathrm{~nm}$. Even at an $\mathrm{RH}$ as low as $50 \%$, substantial cooling induced by the humidified aerosol is observed relative to the dry. This increased cooling effect is increased at higher RHs. In the particle diameter range of $200-500 \mathrm{~nm}$, cooling can be increased by a factor of $1.5-3.5$ at $\mathrm{RH}=90 \%$.

A similar calculation for fractal aggregates would be very interesting yet much more complicated because the amount of exposed surface area would be dependent upon the contact angle between connecting monomers. Also, it is unclear at what RH collapse into a spherical droplet would occur; however, this would be interesting to determine because fractal aggregate collapse into a sphere at a given $\mathrm{RH}$ might have significant consequences for the effectiveness of a fractal aggregate UV shield. Regardless, it is clear that the degree of hygroscopicity exhibited by the early Earth analog aerosols indicates that the humidified aerosol, spherical, or fractal could have a significant cooling or decreased heating effect, depending on the size of the aerosol and the specific RH.

\subsection{Clouds on early Earth}

Photochemical models of haze formation indicate that aerosol present at cloud-relevant altitudes ( $20 \mathrm{~km}$ and below) would be large in size $(D \sim 1 \mu \mathrm{m})$ and sparse in concentration $\left(0.1-10\right.$ particles $\left.\mathrm{cm}^{-3}\right)$. The number concentration is inversely proportional to the particle radius cubed for a fixed mass so that with a mass production rate similar to today's sulfate aerosols, the concentration of these $1 \mu \mathrm{m}$ aerosol particles would likely be about 100 times less than current $0.2 \mu \mathrm{m}$ sulfate CCN (Pavlov et al., 2001a; Wolf and Toon, 2010). It is uncertain whether these large aerosol particles would be spherical or fractal aggregates composed of spherical monomers. Observations on Titan indicate that its organic aerosol particles are fractal aggregates composed of possibly several hundred to several thousand spherical monomer units, each unit roughly $100 \mathrm{~nm}$ in diameter (Tomasko et al., 2005, 2008; Bellucci et al., 2009). However, as aerosol particles descend lower in Titan's atmosphere, there is some evidence that the morphology or composition, or both, change possibly due to $\mathrm{CH}_{4}$ condensing on the aerosol particles (Tomasko et al., 2008). On current-day Earth, collapsing and consequent compaction of soot particles in laboratory simulations to a more spherical shape due to ambient water RH has been observed (Zhang et al., 2008). It is unclear what shape the early Earth organic haze aerosols would have been when exposed to a given RH. In the following calculations of CCN ability of the early Earth analog aerosol, we treat the analog aerosols as perfect spheres with $1 \mu \mathrm{m}$ diameters. Because of the many assumptions the calculations would otherwise require, we neglect any fractal shape. This may underestimate the CCN ability of the aerosol, since theoretical studies have shown that a pair of joined spherical particles will activate at supersaturations much lower than the particles would separately due to the negative curvature of the space at which they are joined and subsequent enhanced capillary action (Crouzet and Marlow, 1995).

The critical supersaturation, $s_{\mathrm{C}}$, defined as the $\mathrm{RH}$ above $100 \%$ for a given dry aerosol diameter at which an aerosol 
will grow rapidly and be activated into a cloud droplet, can be calculated by finding the maximum of $S$ in Eq. 6 for a given $\kappa$-value and dry diameter. Figure 8 shows a plot of $s_{\mathrm{C}}$ versus dry diameter for a range of constant $\kappa$-values, including the early Earth and Titan analog aerosols from this study and other reference materials. According to Fig. 8, a $1 \mu \mathrm{m}$ early Earth analog particle would activate into a cloud droplet well below even a modest supersaturation of $0.1 \%$ (equivalently, $\mathrm{RH}=100.1 \%$ ). In fact, even a relatively small early Earth analog aerosol $200 \mathrm{~nm}$ in diameter would activate at such a low supersaturation. For comparison, the $\mathrm{CCN}$ concentration subset of a population of aerosols is typically defined as what fraction of aerosol is CCN active at $s_{\mathrm{C}}=1 \%$ (Seinfeld and Pandis, 1998). Figure 8 shows that the early Earth analog aerosol would be CCN active at reasonable-and, in fact, low-supersaturations. Because these early Earth analog aerosols are good CCN and are predicted in models to have been present in low concentrations on Archean Earth, they would grow rapidly due to lack of competition for water vapor, fall out as precipitation, and therefore have a short lifetime anywhere critical supersaturation is reached. This "rain without clouds" scenario is similar to one on Titan, which was first suggested by Toon et al. (1988) and reported in observations on Titan (Tokano et al., 2006). On Titan, the optically thin clouds are thought to perhaps provide a constant source of liquid methane drizzle to the surface, which has a significant effect on the surface geology (Tokano et al., 2006). The degree to which such a constant drizzle would have been present on early Earth is unclear and would need to be resolved with modeling.

If there were indeed a dearth of other types of aerosols on most regions of early Earth, the organic haze may have been a main source of CCN. The degree to which the clouds formed from organic haze aerosol would have been optically thin can be estimated by a simple analytical expression from Schwartz and Slingo (1996), which assumes the two-stream approximation and relates the albedo $A_{\mathrm{c}}$ of a non-absorbing, horizontally homogenous cloud optical depth $\tau_{\mathrm{c}}$ :

$$
A_{\mathrm{c}}=\frac{\tau_{\mathrm{c}}\left(1-g_{\mathrm{c}}\right)}{2+\tau_{\mathrm{c}}\left(1-g_{\mathrm{c}}\right)}
$$

Where $g_{c}$ is the asymmetry parameter of the cloud droplets and is approximately 0.85 for particles with radii much smaller than the incident light, a reasonable assumption for cloud droplets. The optical depth $\tau_{\mathrm{c}}$ can, in turn, be estimated by an expression from Schwartz and Slingo (1996) that is a function of cloud droplet concentration $N_{\mathrm{c}}$ :

$$
\tau_{\mathrm{c}} \approx 2 \pi z\left(\frac{3 L}{4 \pi}\right)^{2 / 3} N_{\mathrm{c}}^{1 / 3}
$$

where $z$ is the physical cloud thickness and $L$ is the liquid water volume fraction. By combining Eqs. 9 and 10, the albedo of clouds can be calculated with different droplet concentrations but identical cloud thicknesses and liquid water volume fractions. First, using Eq. 10 and assuming a typical liquid water volume fraction of a cloud, $0.3 \mathrm{~cm}^{3} \mathrm{~m}^{-3}$, we calculate that a cloud with 10 droplets $\mathrm{cm}^{-3}$, perhaps typical of an Archean cloud, has only a third of the optical depth of a cloud with 500 droplets $\mathrm{cm}^{-3}$, more typical of a current-day cloud. By extending this calculation to cloud albedo using Eq. 9, the albedo of the early Earth cloud is 33$80 \%$ that of a current-day cloud over a range of cloud thicknesses, $50-1500 \mathrm{~m}$. The much lower albedo of these Archean clouds could substantially warm the planet. However, this calculation relies on the Wolf and Toon (2010) and Pavlov et al. (2001a) aerosol models for particle concentrations. Both models must make assumptions about wet deposition of aerosols whose hygroscopic properties have not been previously measured. Wolf and Toon (2010) used predictions of cloud formation and rainfall from the model to simulate removal. However, these predictions are based on

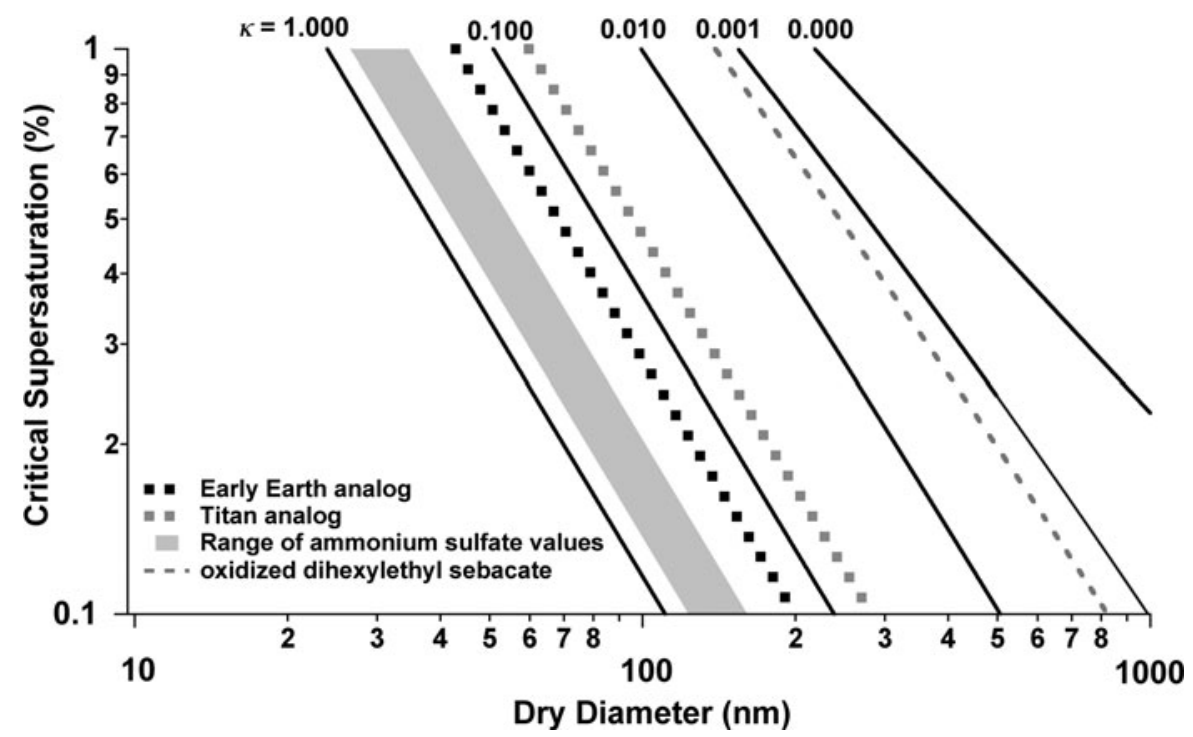

FIG. 8. Critical supersaturation $s_{\mathrm{c}}$ as a function of dry diameter for the early Earth and Titan analog aerosols and other organic and inorganic materials. The top axis shows the corresponding scale for the hygroscopicity parameter $\kappa$. The values of $\kappa$ for the early Earth and Titan analog aerosols are inferred from $f(\mathrm{RH})$ measurements in a subsaturated regime. 


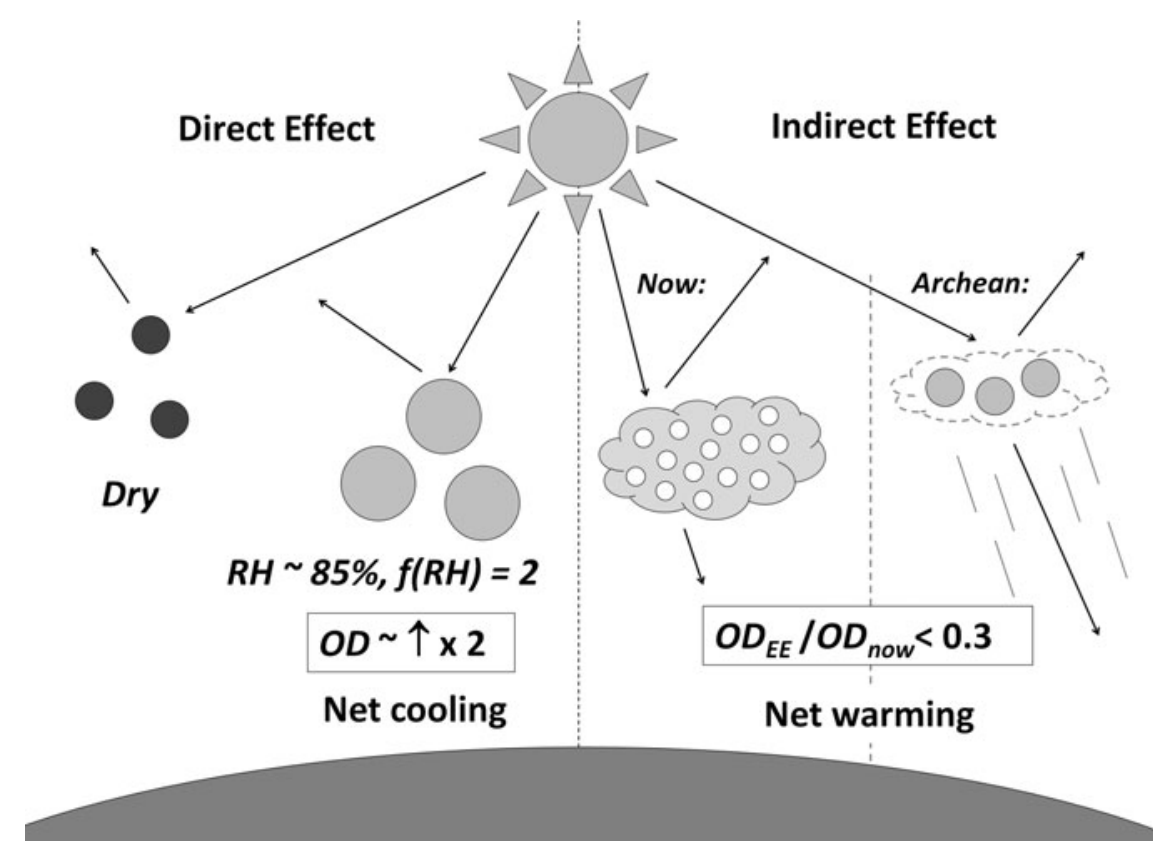

FIG. 9. Summary of the implications of a humidified early Earth haze exposed to humidification and supersaturation for early Earth climate based on the hygroscopicity of the early Earth analog aerosol. The hygroscopic nature of the early Earth analog aerosol from this study indicates that the humidified aerosol, compared to the same aerosol that is dry, would likely have a significant cooling or decreased heating effect, depending on the size of the aerosol and the specific RH. For instance, at an $\mathrm{RH}$ of $85 \%$, the $f(\mathrm{RH})$ of the early Earth analogue is 2, doubling the optical depth (OD) of an aerosol layer. Assuming a typical liquid water volume fraction of a cloud and using Eq. 10, a typical Archean cloud would have only a third of the OD of a cloud with more current-day cloud droplet concentration. Extending this calculation to cloud albedo using Eq. 9 , we find that, over a range of cloud thicknesses, $50-1500$ m, the albedo of the early Earth cloud is 33-80\% that of a current-day cloud. By including the hygroscopic nature of the aerosol and therefore higher rainout rate in aerosol models, the albedo could be even more substantially reduced. The much lower albedo of a typical Archean cloud could substantially warm the planet.

current Earth clouds, which may differ from those on ancient Earth. For a given temperature and ocean coverage, the rainfall rate must be about the same as on present Earth because the evaporation rate only depends on temperature and water availability. However, the rainfall does not need to be distributed in the same way spatially. Pavlov et al. (2001a) prescribed a lifetime of 5 days to organic haze aerosol, which is the same as that of highly soluble gases and that previously assigned to sulfur haze aerosols (Kasting et al., 1989). Such a short lifetime may result in an overestimate of the solubility of an organic haze, underestimate atmospheric particle concentrations, and reduce the warming effect due to optically thin clouds. To resolve how the CCN ability of these aerosols affect climate, the hygroscopicity of early Earth analog aerosol would need to be included in early Earth climate models.

\section{Conclusion}

We measured the hygroscopicity parameter $\kappa=0.22 \pm 0.12$ for early Earth analog aerosol, which enables one to calculate the direct radiative effects at any $\mathrm{RH}$ and their indirect radiative effects based on their CCN ability. Figure 9 shows a schematic that summarizes the implications for the early Earth climate from this work. The degree of hygroscopicity indicates that the humidified aerosol, compared to the same aerosol that is dry, would likely have a significant cooling or decreased heating effect, depending on the size of the aerosol and the specific $\mathrm{RH}$. For instance, at an $\mathrm{RH}$ of $85 \%$, the op- tical growth of the early Earth analog is 2, which means the optical depth of the aerosol layer is doubled. Thus, the growth of particles due to humidification substantially increases the antigreenhouse effect of the haze that is located in regions with humidities greater than about $50 \%$.

Because of the biogenic nature of the haze, DomagalGoldman et al. (2008) and Haqq-Misra et al. (2008) suggested that, regardless of the optical properties of the haze, the degree of cooling it caused on early Earth would have been regulated by a corresponding decrease in $\mathrm{CH}_{4}$ production, which in turn would have reduced haze and restored surface temperatures. However, this negative feedback cycle could have been at least partially offset by a positive feedback cycle involving a UV shield that may have been provided by the haze. If $\mathrm{CH}_{4}$ production was reduced because the antigreenhouse effect of haze was too large, then a thinner haze would have resulted. The thinner haze, while inducing warming, could also have potentially destroyed the organisms' UV shield. The optical properties of the aerosol-both dry and humidified-would have dictated the balance between these two feedback cycles on early Earth.

In contrast, warming relative to current-day clouds is expected due to the indirect effect of the organic haze. The value of the hygroscopicity parameter $\kappa$ measured indicates that the early Earth aerosol could have activated into cloud droplets at reasonable-in fact, low-supersaturations. Photochemical models of the haze predict very low concentrations, compared to current-day Earth standards, 
of micron-sized organic aerosol located $20 \mathrm{~km}$ and lower in altitude. If these aerosol particles were the only particles present, they could activate and grow unimpeded by water-vapor competition of other aerosols, further lowering the particle concentrations than current Archean aerosol models predict. The lifetime of the droplets in these optically thin clouds would be short. If globally present on early Earth, these optically thin clouds would lower the planetary albedo in comparison to today's value and therefore warm the planet. This "rain without clouds" scenario would mean a hydrological cycle very different from the present one.

\section{Acknowledgments}

This material is based on work supported by NASA Exobiology Grant NNXOAAV55G issued through the Office of Space Science. C.A.H. was supported with a National Science Foundation Graduate Research Fellowship. M.A.F. acknowledges support from the NOAA Climate and Global Change Postdoctoral Fellowship Program administered by the University Corporation for Atmospheric Research. M.R.B. was supported by an EPA-STAR fellowship.

\section{Disclosure Statement}

No competing financial interests exist.

\section{Abbreviations}

$\mathrm{CCN}$, cloud condensation nuclei; CRD-AES, cavity ringdown aerosol extinction spectrometer; DMA, differential mobility analyzer; e-AIM, extended Aerosol Inorganic Model; RH, relative humidity.

\section{References}

Andreae, M.O. and Rosenfeld, D. (2008) Aerosol-cloud-precipitation interactions. Part 1 . The nature and sources of cloudactive aerosols. Earth-Science Reviews 89:13-41.

Baynard, T., Lovejoy, E.R., Pettersson, A., Brown, S.S., Lack, D., Osthoff, H., Massoli, P., Ciciora, S., Dube, W.P., and Ravishankara, A.R. (2007) Design and application of a pulsed cavity ring-down aerosol extinction spectrometer for field measurements. Aerosol Sci Technol 41:447-462.

Beaver, M.R., Garland, R.M., Hasenkopf, C.A., Baynard, T., Ravishankara, A.R., and Tolbert, M.A. (2008) A laboratory investigation of the relative humidity dependence of light extinction by organic compounds from lignin combustion. Environ Res Lett 3, doi:10.1088/1748-9326/3/4/045003.

Bellucci, A., Sicardy, B., Drossart, P., Rannou, P., Nicholson, P.D., Hedman, M., Baines, K.H., and Burrati, B. (2009) Titan solar occultation observed by Cassini/VIMS: gas absorption and constraints on aerosol composition. Icarus 201:198-216.

Brooks, S.D., DeMott, P.J., and Kreidenweis, S.M. (2004) Water uptake by particles containing humic materials and mixtures of humic materials with ammonium sulfate. Atmos Environ 38:1859-1868.

Chylek, P. and Wong, J. (1995) Effect of absorbing aerosols on global radiation budget. Geophys Res Lett 22:929-931.

Clegg, S.L., Pitzer, K.S., and Brimblecombe, P. (1992) Thermodynamics of multicomponent, miscible, ionic-solutions. 2. Mixtures including unsymmetrical electrolytes. J Phys Chem 96:9470-9479.
Clegg, S.L., Brimblecombe, P., and Wexler, A.S. (1998) Thermodynamic model of the system $\mathrm{H}^{+}-\mathrm{NH}_{4}^{+}-\mathrm{SO}_{4}^{2}-\mathrm{NO}_{3}-\mathrm{H}_{2} \mathrm{O}$ at tropospheric temperatures. I Phys Chem A 102:21372154.

Cloud, P. (1972) Working model of primitive Earth. Am J Sci 272:537-548.

Collerson, K.D. and Kamber, B.S. (1999) Evolution of the continents and the atmosphere inferred from Th-U-Nb systematics of the depleted mantle. Science 283:1519-1522.

Crouzet, Y. and Marlow, W.H. (1995) Calculations of the equilibrium vapor pressure of water over adhering $50-200 \mathrm{~nm}$ spheres. Aerosol Sci Technol 22:43-59.

DeWitt, H.L., Trainer, M.G., Pavlov, A.A., Hasenkopf, C.A., Aiken, A.C., Jimenez, J.L., McKay, C.P., Toon, O.B., and Tolbert, M.A. (2009) Reduction in haze formation rate on prebiotic Earth in the presence of hydrogen. Astrobiology 9:447-453.

Domagal-Goldman, S.D., Kasting, J.F., Johnston, D.T., and Farquhar, J. (2008) Organic haze, glaciations and multiple sulfur isotopes in the Mid-Archean era. Earth Planet Sci Lett 269: $29-40$.

Dorren, J.D. and Guinan, E.F. (1994) HD-129333 — the Sun in its infancy. Astrophys J 428:805-818.

Duplissy, J., Gysel, M., Alfarra, M.R., Dommen, J., Metzger, A., Prevot, A.S.H., Weingartner, E., Laaksonen, A., Raatikainen, T., Good, N., Turner, S.F., McFiggans, G., and Baltensperger, U. (2008) Cloud forming potential of secondary organic aerosol under near atmospheric conditions. Geophys Res Lett 35, doi:10.1029/2007GL031075.

Engelhart, G.J., Asa-Awuku, A., Nenes, A., and Pandis, S.N. (2008) CCN activity and droplet growth kinetics of fresh and aged monoterpene secondary organic aerosol. Atmos Chem Phys 8:3937-3949.

Farquhar, J., Bao, H.M., and Thiemens, M. (2000) Atmospheric influence of Earth's earliest sulfur cycle. Science 289:756-758.

Flasar, F.M., Achterberg, R.K., Conrath, B.J., Gierasch, P.J., Kunde, V.G., Nixon, C.A., Bjoraker, G.L., Jennings, D.E., Romani, P.N., Simon-Miller, A.A., Bézard, B., Coustenis, A., Irwin, P.G.J., Teanby, N.A., Brasunas, J., Pearl, J.C., Segura, M.E., Carlson, R.C., Mamoutkine, A., Schinder, P.J., Barucci, A., Courtin, R., Fouchet, T., Gautier, D., Lellouch, E., Marten, A., Prangé, R., Vinatier, S., Strobel, D.F., Calcutt, S.B., Read, P.L., Taylor, F.W., Bowles, N., Samuelson, R.E., Orton, G.S., Spilker, L.J., Owen, T.C., Spencer, J.R., Showalter, J.R., Ferrari, C., Abbas, M.M., Raulin, F., Edgington, S., Ade, P., and Wishnow, E.H. (2005) Titan's atmospheric temperatures, winds, and composition. Science 308:975-978.

Gao, Y.G., Chen, S.B., and Yu, L.E. (2007) Efflorescence relative humidity of airborne sodium chloride particles: a theoretical investigation. Atmos Environ 41:2019-2023.

Garland, R.M., Ravishankara, A.R., Lovejoy, E.R., Tolbert, M.A., and Baynard, T. (2007) Parameterization for the relative humidity dependence of light extinction: organic-ammonium sulfate aerosol. J Geophys Res 112, doi:10.1029/2006JD008179.

Goldblatt, C. and Zahnle, K.J. (2010) Clouds and the faint young Sun paradox. Climate of the Past Discussions 6:1163-1207.

Gough, D.O. (1981) Solar interior structure and luminosity variations. Solar Physics 74:21-34.

Grainger, R.G., Lucas, J., Thomas, G.E., and Ewen, G.B.L. (2004) Calculation of Mie derivatives. Appl Opt 43:5386-5393.

Haqq-Misra, J.D., Domagal-Goldman, S.D., Kasting, P.J., and Kasting, J.F. (2008) A revised, hazy methane greenhouse for the Archean Earth. Astrobiology 8:1127-1137. 
Hartz, K.E.H., Rosenorn, T., Ferchak, S.R., Raymond, T.M., Bilde, M., Donahue, N.M., and Pandis, S.N. (2005) Cloud condensation nuclei activation of monoterpene and sesquiterpene secondary organic aerosol. J Geophys Res 110, doi:10.1029/2004JD005754.

Hasenkopf, C.A., Beaver, M.R., Trainer, M.G., DeWitt, H.L., Freedman, M.A., Toon, O.B., McKay, C.P., and Tolbert, M.A. (2010) Optical properties of Titan and early Earth haze laboratory analogs in the mid-visible. Icarus 207:903-913.

Jimenez, J.L., Canagaratna, M.R., Donahue, N.M., Prevot, A.S.H., Zhang, Q., Kroll, J.H., DeCarlo, P.F., Allan, J.D., Coe, H., Ng, N.L., Aiken, A.C., Docherty, K.S., Ulbrich, I.M., Grieshop, A.P., Robinson, A.L., Duplissy, J., Smith, J.D., Wilson, K.R., Lanz, V.A., Hueglin, C., Sun, Y.L., Tian, J., Laaksonen, A., Raatikainen, T., Rautiainen, J., Vaattovaara, P., Ehn, M., Kulmala, M., Tomlinson, J.M., Collins, D.R., Cubison, M.J., Dunlea, E.J., Huffman, J.A., Onasch, T.B., Alfarra, M.R., Williams, P.I., Bower, K., Kondo, Y., Schneider, J., Drewnick, F., Borrmann, S., Weimer, S., Demerjian, K., Salcedo, D., Cottrell, L., Griffin, R., Takami, A., Miyoshi, T., Hatakeyama, S., Shimono, A., Sun, J.Y., Zhang, Y.M., Dzepina, K., Kimmel, J.R., Sueper, D., Jayne, J.T., Herndon, S.C., Trimborn, A.M., Williams, L.R., Wood, E.C., Middlebrook, A.M., Kolb, C.E., Baltensperger, U., and Worsnop, D.R. (2009) Evolution of organic aerosols in the atmosphere. Science 326:1525-1529.

Kasting, J.F., Zahnle, K.J., Pinto, J.P., and Young, A.T. (1989) Sulfur, ultraviolet radiation, and the early evolution of life. Orig Life Evol Biosph 19:95-108.

Khare, B.N., Sagan, C., Arakawa, E.T., Suits, F., Callcott, T.A., and Williams, M.W. (1984) Optical-constants of organic tholins produced in a simulated Titanian atmosphere-from softX-ray to microwave-frequencies. Icarus 60:127-137.

King, S.M., Rosenoern, T., Shilling, J.E., Chen, Q., and Martin, S.T. (2007) Cloud condensation nucleus activity of secondary organic aerosol particles mixed with sulfate. Geophys Res Lett 34, doi:10.1029/2007GL030390.

Knoll, A.H. and Barghoorn, E.S. (1977) Archean microfossils showing cell division from Swaziland and system of South Africa. Science 198:396-398.

Kotzick, R. and Niessner, R. (1999) The effects of aging processes on critical supersaturation ratios of ultrafine carbon aerosols. Atmos Environ 33:2669-2677.

Kump, L.R. and Pollard, D. (2008) Amplification of cretaceous warmth by biological cloud feedbacks. Science 320:195.

Lewis, E.R. (2006) The effect of surface tension (Kelvin effect) on the equilibrium radius of a hygroscopic aqueous aerosol particle. J Aerosol Sci 37:1605-1617.

McKay, C.P., Pollack, J.B., and Courtin, R. (1991) The greenhouse and antigreenhouse effects on Titan. Science 253:1118 1121.

Mojzsis, S.J., Harrison, T.M., and Pidgeon, R.T. (2001) Oxygenisotope evidence from ancient zircons for liquid water at the Earth's surface 4,300 Myr ago. Nature 409:178-181.

Newman, M.J. and Rood, R.T. (1977) Implications of solar evolution for Earth's early atmosphere. Science 198:10351037.

Niemann, H.B., Atreya, S.K., Bauer, S.J., Carignan, G.R., Demick, J.E., Frost, R.L., Gautier, D.J., Haberman, A., Harpold, D.N., Hunten, D.M., Israel, G., Lunine, J.I., Kasprzak, W.T., Owen, T.C., Paulkovich, M., Raulin, F., Raaen, E., and Way, S.H. (2005) The abundances of constituents of Titan's atmosphere from the GCMS instrument on the Huygens probe. Nature 438:779-784.
Pavlov, A.A., Kasting, J.F., Brown, L.L., Rages, K.A., and Freedman, R. (2000) Greenhouse warming by $\mathrm{CH}_{4}$ in the atmosphere of early Earth. J Geophys Res 105:11981-11990.

Pavlov, A.A., Brown, L.L., and Kasting, J.F. (2001a) UV shielding of $\mathrm{NH}_{3}$ and $\mathrm{O}_{2}$ by organic hazes in the Archean atmosphere. $J$ Geophys Res 106:23267-23287.

Pavlov, A.A., Kasting, J.F., Eigenbrode, J.L., and Freeman, K.H. (2001b) Organic haze in Earth's early atmosphere: source of low-C-13 Late Archean kerogens? Geology 29:1003-1006.

Petters, M.D. and Kreidenweis, S.M. (2007) A single parameter representation of hygroscopic growth and cloud condensation nucleus activity. Atmos Chem Phys 7:1961-1971.

Pettersson, A., Lovejoy, E.R., Brock, C.A., Brown, S.S., and Ravishankara, A.R. (2004) Measurement of aerosol optical extinction at $532 \mathrm{~nm}$ with pulsed cavity ringdown spectroscopy. J Aerosol Sci 35:995-1011.

Prenni, A.J., Petters, M.D., Kreidenweis, S.M., DeMott, P.J., and Ziemann, P.J. (2007) Cloud droplet activation of secondary organic aerosol. J Geophys Res 112, doi:10.1029/2006JD007963.

Rogers, R.R. and Yau, M.K. (1996) A Short Course in Cloud Physics, Butterworth-Heinemann, McGill University, Canada.

Rondanelli, R. and Lindzen, R.S. (2010) Can thin cirrus clouds in the tropics provide a solution to the faint young Sun paradox? J Geophys Res 115, doi:10.1029/2009JD012050.

Rosing, M.T., Bird, D.K., Sleep, N.H., and Bjerrum, C.J. (2010) No climate paradox under the faint early Sun. Nature 464:744747.

Rye, R., Kuo, P.H., and Holland, H.D. (1995) Atmospheric carbon dioxide concentrations before 2.2 billion years ago. Nature 378:603-605.

Sagan, C. and Chyba, C. (1997) The early faint Sun paradox: organic shielding of ultraviolet-labile greenhouse gases. Science 276:1217-1221.

Sagan, C. and Mullen, G. (1972) Earth and Mars-evolution of atmospheres and surface temperatures. Science 177:52-56.

Sagan, C. and Pollack, J.B. (1967) Anistropic nonconservative scattering and clouds of Venus. J Geophys Res 72:469-477.

Schopf, J.W., Kudryavtsev, A.B., Czaja, A.D., and Tripathi, A.B. (2007) Evidence of Archean life: stromatolites and microfossils. Precambrian Res 158:141-155.

Schwartz, S.E. and Slingo, A. (1996) Enhanced shortwave radiative forcing due to anthropogenic aerosols. In Clouds Chemistry and Climate, edited by P. Crutzen and V. Ramanathan, Springer, Heidelberg, pp 191-236.

Seinfeld, J.H. and Pandis, S.N. (1998) Atmospheric Chemistry and Physics: From Air Pollution to Climate Change, John Wiley \& Sons, New York.

Sheldon, N.D. (2006) Precambrian paleosols and atmospheric $\mathrm{CO}_{2}$ levels. Precambrian Res 147:148-155.

Svenningsson, B., Rissler, J., Swietlicki, E., Mircea, M., Bilde, M., Facchini, M.C., Decesari, S., Fuzzi, S., Zhou, J., Mønster, J., and Rosenørn, T. (2006) Hygroscopic growth and critical supersaturations for mixed aerosol particles of inorganic and organic compounds of atmospheric relevance. Atmos Chem Phys 6:1937-1952.

Tang, I.N. (1996) Chemical and size effects of hygroscopic aerosols on light scattering coefficients. J Geophys Res 101:19245-19250.

Tokano, T., McKay, C.P., Neubauer, F.M., Atreya, S.K., Ferri, F., Fulchignoni, M., and Niemann, H.B. (2006) Methane drizzle on Titan. Nature 442:432-435.

Tomasko, M.G., Archinal, B., Becker, T., Bézard, B., Bushroe, M., Combes, M., Cook, D., Coustenis, A., de Bergh, C., Dafoe, L.E., Doose, L., Douté, S., Eib, A., Engel, S., Gliem, F., 
Grieger, B., Holso, K., Howington-Kraus, E., Karkoschka, E., Keller, H.U., Kirk, R., Kramm, R., Küppers, M., Lanagan, P., Lellouch, E., Lemmon, M., Lunine, J., McFarlane, E., Moores, J., Prout, G.M., Rizk, B., Rosiek, M., Rueffer, P., Schröder, S.E., Schmitt, B., See, C., Smith, P., Soderblom, L., Thomas, N., and West, R. (2005) Rain, winds and haze during the Huygens probe's descent to Titan's surface. Nature 438:765-778.

Tomasko, M.G., Doose, L., Engel, S., Dafoe, L.E., West, R., Lemmon, M., Karkoschka, E., and See, C. (2008) A model of Titan's aerosols based on measurements made inside the atmosphere. Planet Space Sci 56:669-707.

Toon, O.B., McKay, C.P., Courtin, R., and Ackerman, T.P. (1988) Methane rain on Titan. Icarus 75:255-284.

Trainer, M.G., Pavlov, A.A., DeWitt, H.L., Jimenez, J.L., McKay, C.P., Toon, O.B., and Tolbert, M.A. (2006) Organic haze on Titan and the early Earth. Proc Natl Acad Sci USA 103:18035-18042.

VanReken, T.M., Ng, N.L., Flagan, R.C., and Seinfeld, J.H. (2005) Cloud condensation nucleus activation properties of biogenic secondary organic aerosol. J Geophys Res 110, doi:10.1029/ 2004JD005465.

Walker, J.C.G., Klein, C., Schildlowski, M., Schopf, J.W., Stevenson, D., and Walters, M.R. (1983) Environmental evolution of the Archaean-Early Proterozoic Earth. In The Earth's Earliest Biosphere: Its Origin and Evolution, edited by J.W. Schopf, Princeton University Press, Princeton, NJ, pp 260-290.

Walsh, M.M. (1992) Microfossils and possible microfossils from the early Archean Onverwacht Group, Barberton Mountain Land, South Africa. Precambrian Res 54:271-293.

Wex, H., Stratmann, F., Topping, D., and McFiggans, G. (2008) The Kelvin versus the Raoult term in the Kohler equation. Journal of the Atmospheric Sciences 65:4004-4016.

Wex, H., Petters, M.D., Carrico, C.M., Hallbauer, E., Massling, A., McMeeking, G.R., Poulain, L., Wu, Z., Kreidenweis, S.M., and Stratmann F. (2009) Towards closing the gap between hygroscopic growth and activation for secondary organic aerosol: part 1-evidence from measurements. Atmos Chem Phys 9:3987-3997.

Wexler, A.S. and Clegg, S.L. (2002) Atmospheric aerosol models for systems including the ions $\mathrm{H}^{+}, \mathrm{NH}_{4}^{+}, \mathrm{Na}^{+}, \mathrm{SO}_{4}^{2-}$, $\mathrm{NO}_{3}^{-}, \mathrm{Cl}^{-}, \mathrm{Br}^{-}$and $\mathrm{H}_{2} \mathrm{O}$. J Geophys Res 107, doi:10.1029/ 2001JD000451.

Wilde, S.A., Valley, J.W., Peck, W.H., and Graham, C.M. (2001) Evidence from detrital zircons for the existence of continental crust and oceans on the Earth 4.4 Gyr ago. Nature 409:175-178.

Wiscombe, W.J. and Grams, G.W. (1976) Backscattered fraction in 2-stream approximations. Journal of the Atmospheric Sciences 33:2440-2451.

Wolf, E.T. and Toon, O.B. (2010) Fractal organic hazes provided an ultraviolet shield for early Earth. Science 328:1266-1268.

Zhang, R.Y., Khalizov, A.F., Pagels, J., Zhang, D., Xue, H.X., and McMurry, P.H. (2008) Variability in morphology, hygroscopicity, and optical properties of soot aerosols during atmospheric processing. Proc Natl Acad Sci USA 105:10291-10296.

Address correspondence to: Christa Hasenkopf CIRES

Campus Box 216

CIRES Bldg. Rm. 318

University of Colorado Boulder, CO 80309

USA

E-mail: Christa.Hasenkopf@colorado.edu

Submitted 24 August 2010

Accepted 8 December 2010 
